\title{
An Integrated Flywheel Energy Storage System With Homopolar Inductor Motor/Generator and High-Frequency Drive
}

\author{
Perry Tsao, Member, IEEE, Matthew Senesky, Student Member, IEEE, and Seth R. Sanders, Member, IEEE
}

\begin{abstract}
The design, construction, and test of an integrated flywheel energy storage system with a homopolar inductor motor/generator and high-frequency drive is presented in this paper. The work is presented as an integrated design of flywheel system, motor, drive, and controller. The motor design features low rotor losses, a slotless stator, construction from robust and low cost materials, and a rotor that also serves as the energy storage rotor for the flywheel system. A high-frequency six-step drive scheme is used in place of pulsewidth modulation because of the high electrical frequencies. A speed-sensorless controller that works without state estimation is also described. A prototype of the flywheel system has been demonstrated at a power level of $9.4 \mathrm{~kW}$, with an average system efficiency of $83 \%$ over a

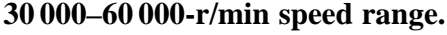

Index Terms-Flywheel energy storage, high-frequency motor drive, homopolar inductor alternator, homopolar inductor motor, integrated flywheel, sensorless motor control, six-step drive.

\section{INTRODUCTION}

$\mathbf{T}$ HIS PAPER presents the design, construction, and test of an integrated flywheel energy storage system with a high-speed homopolar inductor motor/generator, high-frequency drive, and speed-sensorless control scheme. The contributions of this paper center around four main areas: integrated flywheel design, flywheel motor design, high-frequency drive design, and sensorless control design.

Firstly, a description of the advantages of integrated flywheel energy storage systems, and a design methodology for these systems is presented. An integrated flywheel system is one in which the energy storage accumulator and the electromagnetic rotor are combined in a single-piece solid steel rotor. This allows the housing of the motor to comprise a large part of the vacuum and burst containment of the flywheel, enabling significant savings in total system weight and volume. By using an integrated design, the energy storage density of a high power steel rotor fly-

Paper IPCSD 03-097, presented at the 2002 Industry Applications Society Annual Meeting, Pittsburgh, PA, October 13-18, and approved for publication in the IEEE TRANSACTIONS ON INDUSTRY APPLICATIONS by the Electric Machines Committee of the IEEE Industry Applications Society. Manuscript submitted for review September 16, 2002 and released for publication July 23, 2003. This work was supported in part by the National Science Foundation under Grant ECS-9906607

P. Tsao was with the Department of Electrical Engineering and Computer Science, University of California, Berkeley, CA 94720 USA. He is now with United Defense, L.P., Santa Clara, CA 95050 USA (e-mail: perry.tsao@udlp.com).

M. Senesky and S. R. Sanders are with the Department of Electrical Engineering and Computer Science, University of California, Berkeley, CA 94720

USA (e-mail: senesky@eecs.berkeley.edu; sanders@eecs.berkeley.edu).

Digital Object Identifier 10.1109/TIA.2003.818992 wheel energy storage system can approach that of a composite rotor system, but avoid the cost and technical difficulties associated with a composite rotor.

Secondly, we describe how homopolar inductor motors are well suited for flywheel energy storage applications, and particularly well suited for integrated flywheel designs.

Thirdly, we describe a fixed-voltage six-step drive that can achieve high efficiency over a 2:1 speed range at electrical frequencies beyond those practical for insulated gate bipolar transistor (IGBT) pulsewidth-modulation (PWM) drives.

Finally, a speed-sensorless control scheme which enables closed-loop operation at high electrical frequencies is presented. An advantage of this control scheme is that it does not require state estimation of rotor position or speed, thus making it very insensitive to motor parameters.

As a demonstration of the above concepts, a prototype integrated flywheel energy storage system incorporating a homopolar inductor motor, high-frequency six-step drive, and sensorless control is built and its experimental results are presented. An analysis of harmonic currents induced by the six-step drive and associated copper and rotor losses is given in the appendixes.

This paper is based on work first presented in [1]. A more detailed treatment of this work is presented in [2], and the speedsensorless control is further developed in [3].

\section{INTEGRATED FLYWHEEL DESIGN}

In contrast to many contemporary flywheel systems, in an integrated flywheel system the same rotor is used for both the motor/generator and energy storage functions. Some examples of integrated flywheels include [4] and [5], while the designs presented in [6]-[8] are not considered integrated because the bulk of the energy is stored in the portion of the rotor made of composite material, and the electromagnetic portion of the rotor is primarily used for torque production by the motor/generator. The advantages of an integrated flywheel design include reduced system weight, lower component count, reduced material costs, lower mechanical complexity, and reduced manufacturing cost.

Many flywheels are built with composite rotors because of the higher strength-to-weight ratio of composites versus steel. Unfortunately, the strength advantage is reduced by the additional mechanical complexity of a composite rotor and the safety derating factor necessary for composites. The derating is necessary because the failure behavior for composite materials is more dif- 
ficult to predict than for steel. Composite rotors also impose a stricter limit on the rotor operating temperature.

Furthermore, while a composite flywheel of a certain energy storage capacity may have a lighter rotor than a steel flywheel system of the same energy storage capacity, the rotor itself is only a a small fraction of the overall flywheel system weight. Since the remainder of the system, such as the stator, containment, and electronics remain basically the same, the reduction in weight is a small percentage of the total system weight. This is particularly true for high power flywheels designed for discharges in the range of tens of seconds. Since many flywheel systems are aimed at power quality and hybrid vehicle loadleveling applications that require short, high-power discharges, many of them fall into this category. However, because the mass of the electromagnetic rotor and stator is a function of power, for flywheels with a high ratio of power versus energy storage, the electromagnetic portions of the rotor and stator will comprise an even larger portion of the system mass, further reducing the advantage of composite rotors.

In a similar manner, the vacuum and burst containment necessary for composite rotors also offsets their advantages over steel rotors, especially when compared to an integrated design where a large portion of the containment structure is comprised by the motor stator and housing.

Perhaps the most attractive feature of a steel rotor integrated flywheel design is that it is similar in material composition, design, and complexity to a standard electric machine, therefore it is reasonable to expect that for volume production the manufacturing costs of such a flywheel would be comparable to those of a similarly sized electric machine. Thus, the cost of the flywheel hardware may be estimated from its design weight.

In conclusion, the motivation and goal in this work is to demonstrate that a high power integrated flywheel system with a steel rotor can achieve similar performance to a composite rotor flywheel system, with less complexity, lower manufacturing costs, and lower material costs.

\section{A. Flywheel Motor Requirements and Motor Selection}

High efficiency, a robust rotor structure, low zero torque spinning losses, and low rotor losses are the key requirements for a flywheel system's motor/generator. High efficiency is required so that the flywheel can be an effective energy storage medium. Motor efficiency must be high over the entire speed and power range of operation. In addition, the zero torque spinning losses of the machine must be very low, since for many applications the flywheel is idling most of the time. A robust rotor structure is necessary for obvious reliability and safety reasons. The design parameters for the machine presented here are shown in Table I.

The third requirement of low rotor losses is also critical and drives many of the design decisions in a flywheel system. Because high-speed flywheels operate in a vacuum to reduce windage losses, the main paths for heat transfer from the rotor are through radiation and through the bearings (if ball bearings are used). The amount of heat transfer through radiation is small except at high temperatures, and the thermal path through the bearings is minimal, therefore, controlling the rotor losses
TABLE I

MACHINE DESIGN PARAMETERS

\begin{tabular}{c|c}
\hline Max. Power & $30 \mathrm{~kW}$ \\
Max. Speed & $100,000 \mathrm{rpm}$ \\
Energy storage capacity & $140 \mathrm{~W} \cdot \mathrm{hr}$ \\
System mass & $36 \mathrm{~kg}$ \\
Power density & $833 \mathrm{~W} / \mathrm{kg}$ \\
Energy density & $3.9 \mathrm{~W} \cdot \mathrm{hr} / \mathrm{kg}$ \\
\hline
\end{tabular}

is critical to prevent overheating of the rotor. This requirement rules out machines such as induction machines and switched reluctance machines because of their respective conduction and core losses on the rotor. The remaining motors to consider are the synchronous type: permanent magnet (PM), synchronous reluctance (SR), and homopolar inductor motors, among others.

PM motors are currently the most commonly used motors for flywheel systems [7]-[9]. While they have the advantages of high efficiency and low rotor losses, the presence of PMs on the rotor makes the rotor more temperature sensitive (thus requiring even lower rotor losses), and the mechanical structure of the rotor more complicated because of the brittleness and low strength of the PMs. The cost of the PMs, especially the high-temperature Sm-Co type, can also be considerable.

SR motors are also used in some flywheel systems. They can also have high efficiency, low rotor losses, and low zero torque spinning losses. Unfortunately, it is difficult to construct an SR rotor with a high $L_{d} / L_{q}$ ratio while maintaining a robust rotor structure. Examples of SR rotors constructed using several axially bonded sheets of high strength steel as in [6] and [10] have been made, however this leads to a lower $L_{d} / L_{q}$ ratio which in turn leads to a lower power factor. Lower power factor increases the required VA rating of the drive and can add significantly to the cost of the system.

All three of these motor types, PM, SR, and homopolar inductor, share the advantage of high efficiency, however PM rotors tend to be more temperature sensitive, mechanically complex, and costly; and solid rotor SR motors have either complex rotor structures or low power factors. While these issues can be overcome, homopolar inductor motors present an attractive alternative with a low-cost rotor machined from a single piece of steel that is more robust and less temperature sensitive than PM or SR rotors. In addition, a homopolar inductor motor with a slotless stator and six-step drive eliminates stator slot harmonics and maintains low rotor losses while also allowing operation at unity (or any desired) power factor.

These advantages of robust rotor structure, high power factor, and low rotor losses make homopolar inductor motors particularly well-suited for flywheel energy storage applications.

\section{B. Homopolar Inductor Motor Characteristics}

Although not widely used in practice, homopolar inductor motors have been researched for a variety of applications. They are sometimes referred to as "synchronous homopolar motors" [1], [3], [11], or "homopolar motors" [12], [13], but "homopolar inductor motor" [14]-[16] is also commonly used and will be the term applied in this paper. The defining feature of these motors is the homopolar $d$-axis magnetic field created by a field 


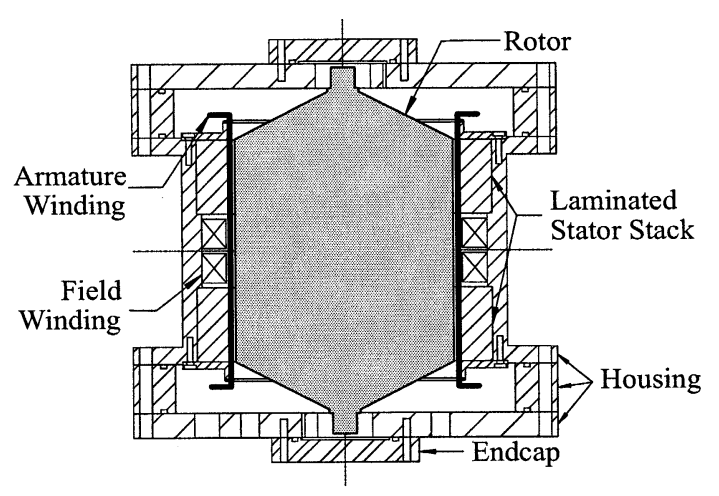

Fig. 1. Cutaway view of motor.

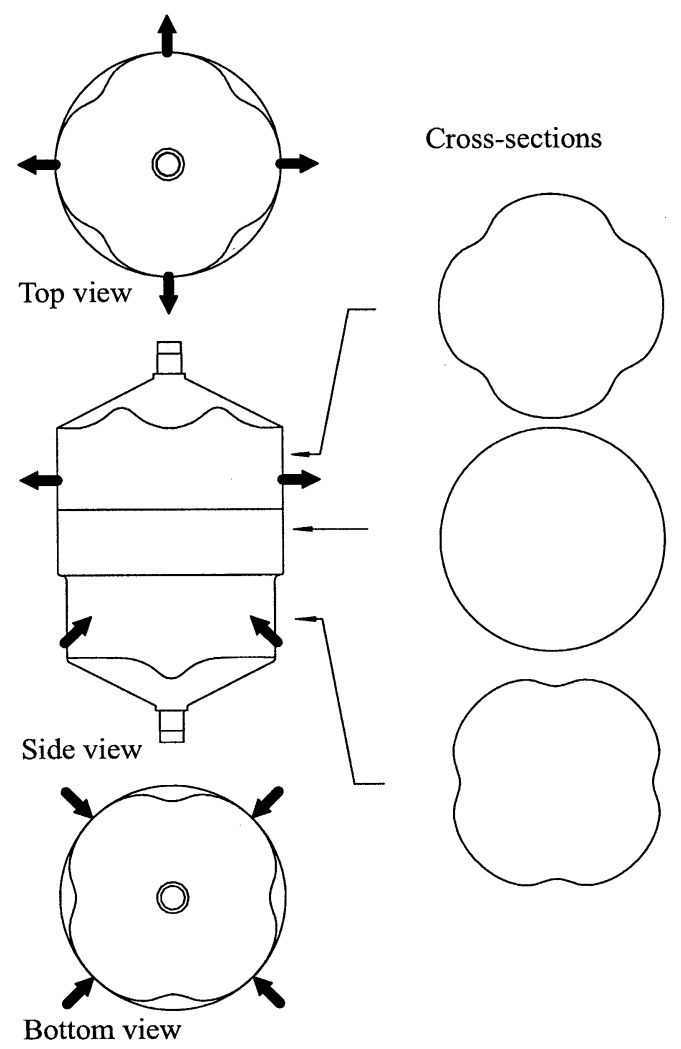

Fig. 2. Top, side, and bottom views of rotor with cross sections showing the rotor profile in each of the three sections. Dark arrows indicate the paths of the magnetizing flux generated by the field winding.

winding [4], [11], [13]-[15], PMs, or a combination of PMs and windings [12]. The principle is the same as in a traditional synchronous generator, with which the homopolar inductor motor has similar terminal characteristics. However, in the case of the homopolar inductor motor, the field winding is fixed to the stator and encircles the rotor rather than being placed on the rotor, as shown in Fig. 1. The field winding and the magnetizing flux path in the present motor design are shown schematically in Fig. 2. Note that the rotor pole faces on the upper part of the rotor are offset from the pole faces on the lower part (see Figs. 2 and 3).

There are several advantages to having the field winding in the stator. Among these are elimination of slip rings and greatly simplified rotor construction, making it practical to construct the rotor from a single piece of high strength steel. This feature

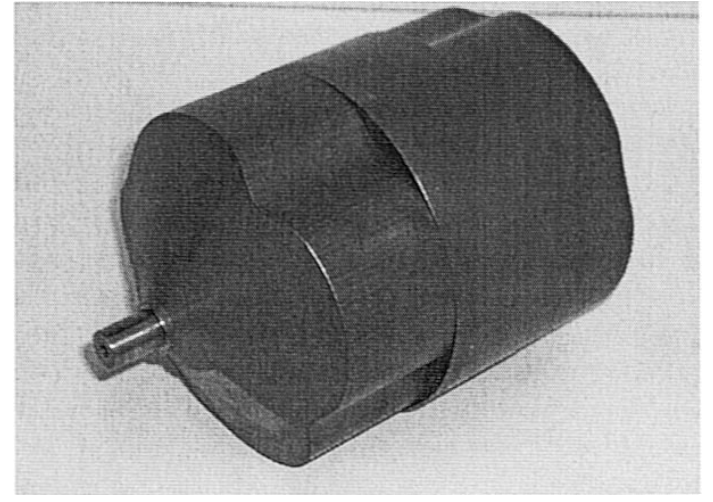

Fig. 3. Photograph of prototype rotor. Rotor is $11.2 \mathrm{~cm}$ in diameter, with an active length of $11.5 \mathrm{~cm}$, and total length of $20.0 \mathrm{~cm}$.

makes homopolar motors very attractive for high-speed operation; a single piece steel rotor is used in the design presented here and in [4], [11], [14]. Other homopolar rotor designs include laminations [13], PMs [12], or other nonmagnetic structural elements to increase strength and reduce windage losses [15]. Additional advantages of having the field winding in the stator include ease in cooling the field winding and increased volume available for this winding. The large volume available for the field winding allows high flux levels to be achieved efficiently, making a slotless stator design feasible.

As described previously, the slotless stator is an advantage for solid rotor machines because it eliminates slotting induced rotor losses [10]. A slotless stator also allows for higher gap flux densities because saturation of the stator teeth is no longer a concern. The design principle is similar to a slotless PM machine, with the advantage that the magnetizing field can be controlled to keep efficiency high at low and zero torque. A possible disadvantage of the slotless stator is the difficulty in constructing the armature winding, which must be bonded to the smooth inner bore of the stator iron. As described in Section II-E, a relatively simple and effective process was developed in this work to construct the winding.

\section{Flywheel Design Methodology}

This section describes the process used in the design of the flywheel energy storage system. The first step in the design process was the selection of $300 \mathrm{M}$ alloy steel for the rotor. This is a low alloy steel very similar to AISI 4340 in composition that can be hardened to an ultimate strength of $2.0 \mathrm{GPa}(290 \mathrm{ksi})$. It was chosen because of its high strength, availability, relatively low cost, and high fatigue strength of $1.0 \mathrm{GPa}(145 \mathrm{ksi})$ for over 1000000 cycles [17].

The next step was to calculate the necessary rotor volume to achieve the goal of $500 \mathrm{~kJ}(140 \mathrm{~W} \cdot \mathrm{h})$ of energy storage. The energy storage capacity of a rotating cylindrical rotor is determined from the ultimate strength $\sigma_{u}$ of the rotor material and the rotor volume $\mathrm{Vol}_{r}$ with this expression [18]:

$$
E_{\text {stored }}=K \cdot \sigma_{u} \cdot \operatorname{Vol}_{r} .
$$

A safety margin of 0.5 for the ultimate strength, a shape factor of 0.60 , and a speed range factor of $3 / 4$ were incorporated into the constant $K$. The speed range factor accounts for the 2:1 


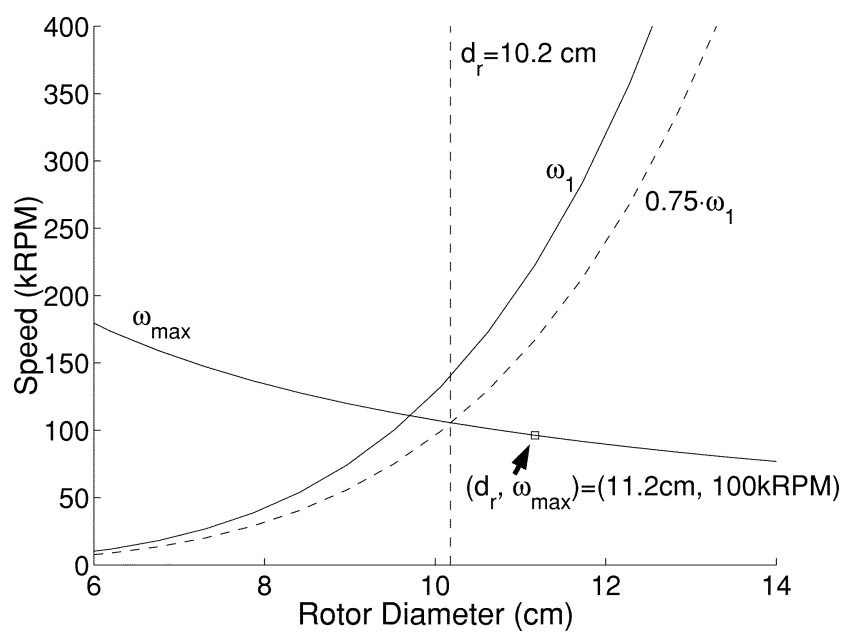

Fig. 4. Plot of rotor maximum speed $\omega_{\max }$ and bending mode $\omega_{1}$ as a function of rotor diameter. The vertical dashed line indicates the minimum diameter rotor that can spin up to its maximum speed $\omega_{\max }$ without approaching the bending mode speed. The $0.75 \cdot \omega_{1}$ line indicates the margin of safety. The square denotes the diameter and maximum speed of the prototype rotor.

speed range from $1 / 2 \omega_{\max }$ to $\omega_{\max }$, which implies that $3 / 4$ of the maximum kinetic energy is recovered. Using these factors, the volume of rotor necessary to meet the energy storage goal was determined to be $1100 \mathrm{~cm}^{3}$.

The next step was to choose the aspect ratio of the rotor. The choice varies between rotors that are long with a small radius to ones that are short with a large radius. The range of appropriate shapes is restricted by examining the first bending modes. Fig. 4 plots the maximum speed $\omega_{\max }$ needed to obtain $500 \mathrm{~kJ}$ of energy storage and the first bending mode $\omega_{1}$ for a range of rotor diameters. The data is calculated for rotors constructed out of $300 \mathrm{M}$ steel with a volume equal to the previously calculated $1100 \mathrm{~cm}^{3}$. The dashed curve in the figure indicates $0.75 \omega_{1}$, the desired margin of safety for the operating speed. From Fig. 4, it can be determined that to achieve $500 \mathrm{~kJ}$ of energy storage in a rotor with a diameter less than $10.2 \mathrm{~cm}$ would require operating near or above the first bending mode, which is undesirable because it could cause large amplitude vibrations that can damage the system if not controlled.

Using the above criteria, a range of rotors was selected and an optimization was conducted. The goal of the optimization was to find, given a rotor of a particular aspect ratio, the best stator design, rotor design, and operating point to minimize losses at the worst-case full-power operation. The worst-case full-power operating point occurs at peak power at the minimum speed, in this case, $30 \mathrm{~kW}$ at a speed of $1 / 2 \omega_{\max }$. The parameters varied are shown in Table II, and include the magnetic gap $g$, armature and field winding dimensions, rotor saliency, and operating point values. The constraints on the optimization included maximum stator volume (set as a multiple of the rotor volume), saturation flux of $1.5 \mathrm{~T}$ in the stator, and minimum air gap to ensure adequate mechanical clearances. The efficiency was evaluated using lumped parameter calculations of the magnetic paths and inductances, conduction losses, and core losses. The optimization was implemented in MATLAB using the "fmincon" constrained gradient minimization algorithm in the MATLAB Op-
TABLE II

OPTIMIZATION RESULTS

\begin{tabular}{l|l}
\hline Parameter & $\begin{array}{l}\text { Prototype } \\
\text { Value }\end{array}$ \\
\hline Unoptimized (Given) parameters & \\
Rotor diameter $d_{r}$ & $11.2 \mathrm{~cm}$ \\
Rotor length $l_{r}$ & $11.5 \mathrm{~cm}$ \\
Rotor volume $V o l_{r}$ & $1,100 \mathrm{~cm}^{3}$ \\
Rotor mass & $9.5 \mathrm{~kg}$ \\
Rotor inertia & $0.0133 \mathrm{~kg} / \mathrm{m}^{2}$ \\
Stator Material & $0.005 " \mathrm{SiFe}$ lams \\
Housing Vol. & $10,650 \mathrm{~cm}^{3}$ \\
Housing Dimensions & $22 \mathrm{~cm} \times 22 \mathrm{~cm}$ \\
& $\times 22 \mathrm{~cm}$ \\
Optimized parameters & \\
Stator geometry & $0.216 \mathrm{~cm}$ \\
Magnetic gap $g$ & $0.130 \mathrm{~cm}$ \\
Armature winding thickness $t_{\text {arm }}$ & $11.5 \mathrm{~cm}$ \\
Field winding inner dia. $i d_{f w}$ & $15 \mathrm{~cm}$ \\
$\quad$ Outer dia. od $d_{f w}$ & $3.8 \mathrm{~cm}$ \\
Roight $l_{f w}$ & \\
Rotor Geometry & 1 \\
$L_{d} / L_{q}$ ratio & $11.5 \mathrm{~A}$ \\
Operating point & $96 \mathrm{~A}$ \\
Field winding current $I f$ & 0.996 \\
Armature current $I$ & $208 \mathrm{~V}$ \\
Power factor $p f$ & $13 \mu \mathrm{H}$ \\
Voltage $V$ Resulting parameters & $1.35 \mathrm{mH}$ \\
$L$ & $95 \%$ \\
$L_{M} \quad$ & \\
Efficiency @ $50 \mathrm{krpm}, 30 \mathrm{~kW}$ & \\
\hline
\end{tabular}

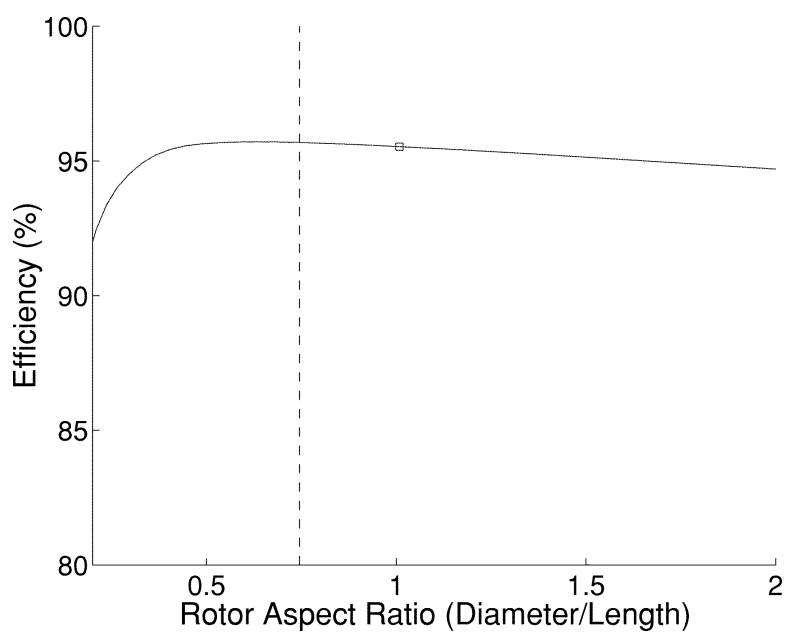

Fig. 5. Plot of optimization results for worst case full-power machine efficiency as a function of rotor aspect ratio. The square indicates the calculated efficiency for the prototype rotor, and the vertical dashed line matches that of Fig. 4, indicating minimum aspect ratio.

timization toolbox. The optimized parameters and the results are described in Table II.

The results of the optimization are plotted in Fig. 5. The shorter, larger radius rotors tended to have lower efficiency primarily because the field winding encircles a wider rotor. The efficiency of the very long, smaller diameter rotors decreases because a flux limit imposed by the axial saturation of the middle section of the rotor is reached. The optimization suggests that the highest efficiency machine that still operates below the first 


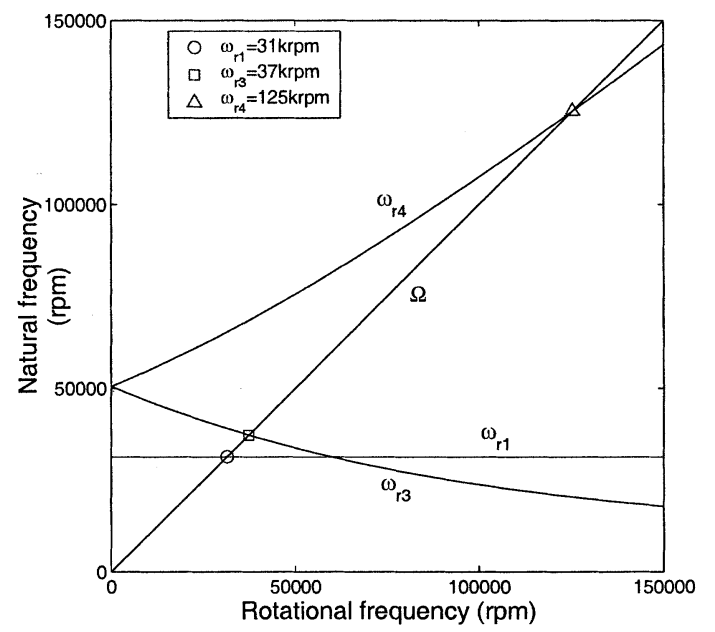

Fig. 6. Plot of the natural frequencies of the rotor as a function of rotor speed $\Omega$, and the resonances which occur when the natural frequencies intersect with $\Omega$. From this plot it can be seen that all three of these resonance speeds fall outside the target operating speed range of 50-100 kr/min.

bending mode speed would have a rotor diameter of $10.2 \mathrm{~cm}$. Because of practical considerations related to construction of the prototype, such as available Litz wire sizes, the dimensions of the prototype differed slightly from the optimum as determined by the design process. The values in Table II are those of the prototype.

The parameter that had the most important effect on performance was the magnetic gap $g$, which is defined as the distance between the outer diameter of the rotor and the inner diameter of the stator laminations. In the efficiency optimization, increasing $g$ had the effect of increasing the volume for the armature windings, thus decreasing stator resistance while increasing the field winding excitation necessary to achieve a certain flux level. In essence, varying $g$ trades off the torque-producing efficiency of the armature for the torque producing efficiency of the field winding.

Adjustment of the gap dimension also allows for adjustment of the power rating of the machine. Larger gaps admit more armature copper and correspondingly higher armature currents, at the cost of increased field excitation requirements. Thus, the rating of this type of machine can easily be adjusted for a specific target power. The parameters indicated in Tables I and II reflect a possible rating for application in hybrid electric vehicles and power quality.

The final consideration is to ensure that there are no rotor resonances in the operating speed. Since by design the rotor will be operating below the first bending mode $w_{1}$, the resonances of concern are the rigid-body translational $\left(\omega_{r 1}=\omega_{r 2}\right)$ and angular resonances $\left(\omega_{r 3}\right.$ and $\left.\omega_{r 4}\right)$ that arise from supporting the rotor on compliant bearings. The translational and angular resonances both depend on the stiffness of the bearings and the mass of the rotor, while the angular resonances depend on the additional factor of the ratio of the polar and diametral moments of inertia $I_{p}$ and $I_{d}$ [19]. A stiffness of $k_{\text {bear }}=75.8 \times 10^{6} \mathrm{~N} / \mathrm{m}$ for the bearing mounts was selected for the chosen rotor design so that all three of these resonance speeds fell outside the operating speed range, as shown in Fig. 6.

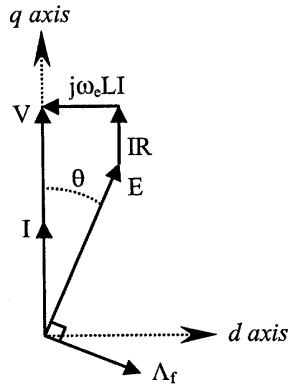

Fig. 7. Motor vector diagram, with inverter operating at unity power factor, $p f=1$.

\section{Six-Step Drive Strategy}

The high synchronous electrical frequencies of this motor are partially due to the fact that it is an eight-pole design. Although the high electrical frequency increases the demands on the inverter, having a high pole number also reduces the size of the stator iron and thus the overall weight. In this sense, a high frequency drive enables us to design a more compact flywheel. For this flywheel system, the peak electrical frequency $(6.6 \mathrm{kHz}$ at $100 \mathrm{kr} / \mathrm{min}$ ) makes a standard PWM drive scheme with IGBTs impractical. Drive efficiency is also a concern; we wish to minimize switching loss in the inverter, conduction loss in both the inverter and the machine, and core loss in the machine.

In consideration of the above issues, two distinct but related choices were made. The first decision was to use six-step drive operating from a fixed-voltage dc bus. The second decision was to drive the inverter at unity power factor. The reasons and consequences for both of these decisions on the inverter and the motor are described in this section.

For the inverter, the obvious benefit of six-step operation is that switching losses are considerably lower than for PWM, since the maximum switching frequency for any one switching element is the machine's electrical frequency, in this case between $3.3-6.6 \mathrm{kHz}$. This frequency is relatively low for modern IGBT technology. Operation at unity power factor minimizes the inverter current for a given power level, resulting in the most efficient use of the inverter $V A$ rating. In addition, zero-current switching (ZCS) occurs for six-step drives when operating at unity power factor. This is in contrast to PWM which has neither ZCS nor zero-voltage switching (ZVS).

For the motor, it is first noted that high efficiency can be maintained at full power over the entire $2: 1$ speed range while running with a fixed voltage. This is possible for homopolar inductor motors because of the capability to adjust the back electromotive force (EMF) with the field winding. Secondly, operating at unity power factor has little impact on efficiency because in the design presented here it is very close to the optimal operating point. The optimal angle for the current $I$ (as determined from the optimization process described in Section II-C ) would be aligned with the back EMF $E$, but $\theta$ is less than $5^{\circ}$ at full power, and even smaller at lower power levels. Therefore, aligning $I$ with $V$ (see Fig. 7) represents only a small shift in the operating point, and therefore only a small impact on efficiency.

The last consideration for the motor is losses from harmonics in the six-step waveform. Since the six-step drive precludes all 


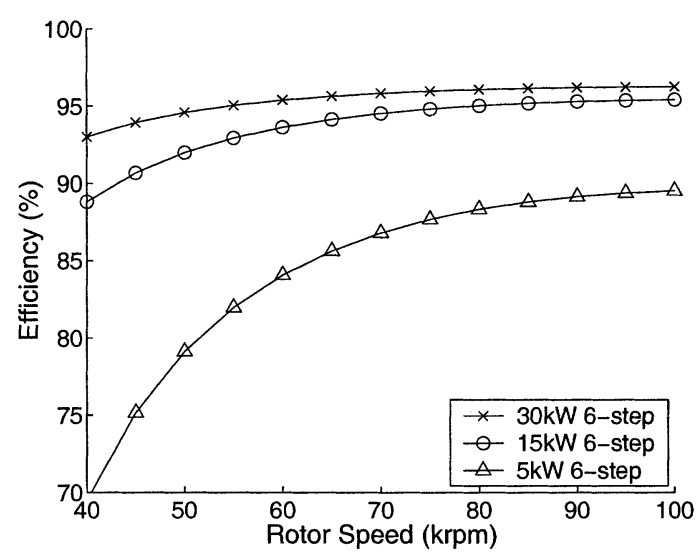

Fig. 8. Plot of simulated system efficiency versus speed at various power levels for six-step drive of the prototype machine.

triple-n harmonics with an open neutral connection, the main time harmonics seen by the machine are the 5 th and 7 th $(6 k \pm 1)$ harmonics and the core loss should not be significantly higher than that of a sinusoidal drive. As noted in [20], [21], six-step waveforms result in lower core losses than PWM, and only slightly higher core losses than sinusoidal waveforms in induction machine drives, and those results should also carry over to the stator core losses in the homopolar inductor machine discussed here. In Appendixes A-D, it is shown that with proper sizing of the phase inductance $L_{a}$, the harmonic conduction and rotor losses can also be made small. For the $50-100-\mathrm{kr} / \mathrm{min}$ speed range with voltage $V=160 \mathrm{~V}$, an armature inductance of $L_{a}=33 \mu \mathrm{H}$ is appropriate.

The efficiency of six-step and unity power factor operation is seen in Fig. 8, which plots the calculated efficiencies of the flywheel system with a fixed-voltage six-step drive at unity power factor with a properly sized inductance to reduce harmonic losses. While the efficiency does drop at lower power levels, it still remains adequate even at $5 \mathrm{~kW}$. Efficient operation at even lower average power levels is possible by running in a pulse mode.

Fig. 9 breaks down the three main loss components as a percentage of the total loss for different power levels. At low speeds the field winding loss is higher and the armature loss is lower for a fixed voltage drive. The reason for this is that the back EMF is kept nearly constant with a fixed-voltage drive, which requires more field-winding excitation at lower speeds. In addition, since the back EMF is also nearly independent of the power level, at low power levels the percentage of the total loss due to the field winding and core loss dominate since the armature currents are relatively small.

In summary, a six-step inverter drive has many benefits over a PWM drive in this application, and operating at unity power factor has considerable benefits in terms of the inverter $V A$ rating.

\section{E. Prototype Construction}

The dimensions and other important parameters for the prototype are shown in Tables I and II. The rotor for the machine consists of a single piece of high strength steel. As shown in Fig. 2, four poles are cut into both the upper and lower parts of
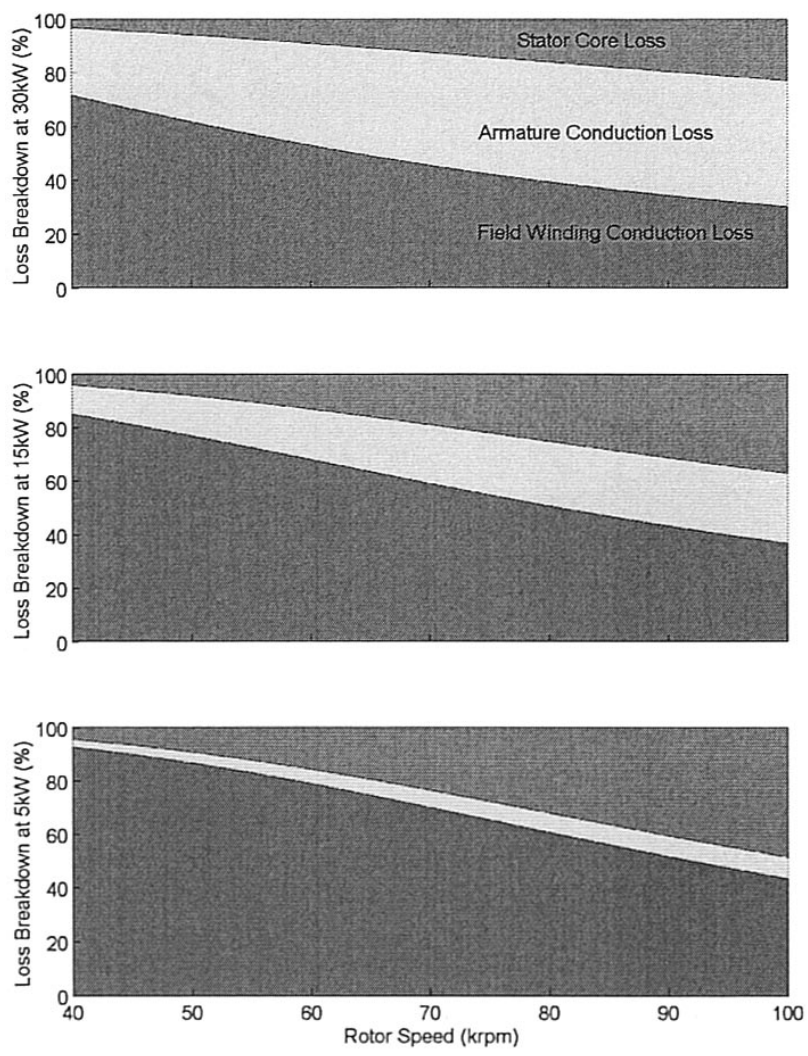

Fig. 9. Breakdown of calculated losses as a percentage of the total loss versus rotor speed for the prototype machine. Plots are shown for 30,15 , and $5 \mathrm{~kW}$. The labels for the loss components in the $30-\mathrm{kW}$ plot also apply to the other plots.

the rotor with the lower poles rotated $45^{\circ}$ with respect to the upper poles. The center portion of the rotor is cylindrical, and the field winding encircles this portion of the rotor. The four upper poles are all the same magnetic polarity $(\mathrm{N})$, and the flux returns down through the back iron to the lower set of poles (S). The machine has eight poles, and no saliency, i.e., $L_{d} / L_{q}=1$. The stator is made from 0.005 " thick laminations, stacked and press-fit into a steel tube that serves as both the back iron and housing for the machine. Only the field winding flux and not the alternating flux of the armature travels through the back iron, so core loss in the back iron is not an issue. The field winding was wound around a bobbin and also pressed into the back iron. An aluminum bobbin was used for thermal and structural considerations.

The most challenging part of the prototype construction was the winding of the stator armature. The armature was formed from rectangular Litz wire bonded to the inner bore using thin sheets of FR4 prepreg. FR4 prepreg is the partially cured form of the yellow-green epoxy-fiberglass laminate commonly used as printed circuit board substrate. The FR4 employed here had a thickness of $63.5 \mu \mathrm{m}$ (0.0025 in). A diagram of the construction assembly is shown in Fig. 10. First, a layer of FR4 was placed against the inner bore, followed by the windings, and then an additional layer of FR4 on the inside of the windings. Then an air bladder was inserted and inflated to $1 \mathrm{~atm}$ (15 psi) to compress the FR4-Litz wire-FR4 assembly against the inner bore. The stator assembly was then baked in an oven to reflow and fully cure the epoxy in the FR4. After baking, the air bladder was 


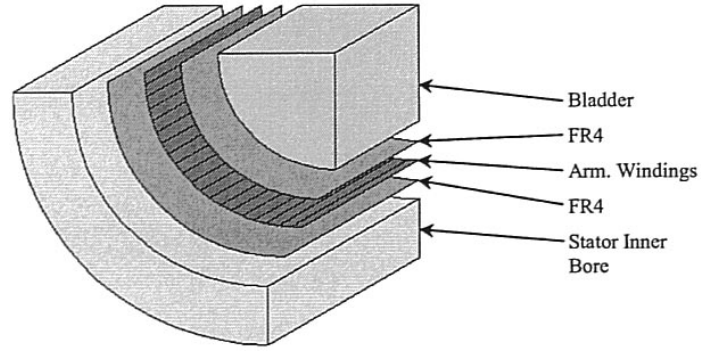

Fig. 10. Diagram of process for bonding winding to the slotless stator. Drawing is a cutaway view of $1 / 4$ of stator. A layer of partially cured FR4 is placed against the inner bore of the stator, followed by the windings, and then another layer of FR4. An inflatable bladder is used to compress the assembly, and then the assembly is baked to reflow the epoxy in the FR4 and fully cure it.

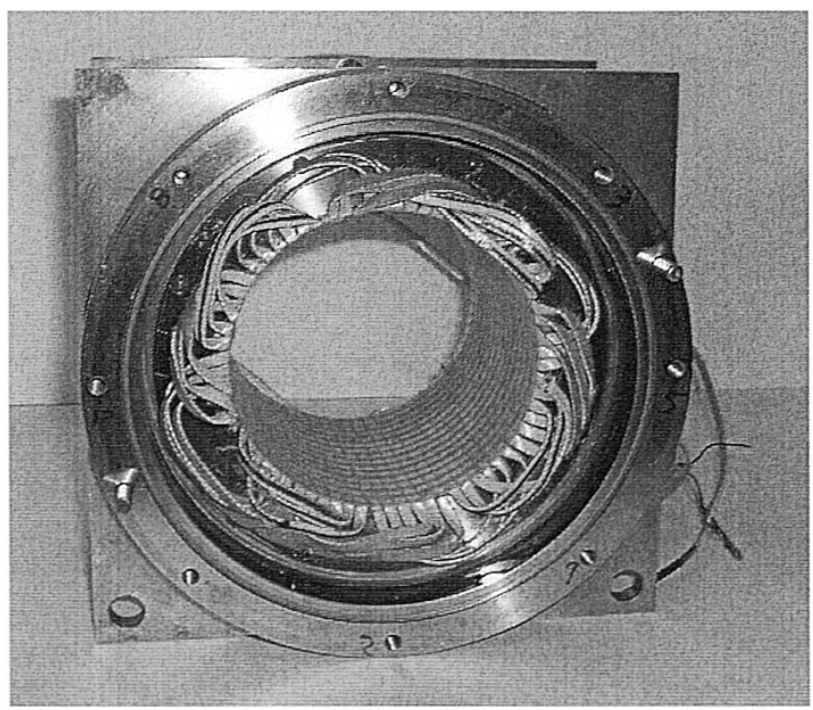

Fig. 11. View of stator and armature winding.

removed, and the result was a smooth and solid winding structure bonded tightly to the inner bore of the motor. Photographs of the completed armature are shown in Figs. 11 and 12.

A compliant bearing mount was also designed and built to allow the rotor to operate at speeds above resonance. The first resonant mode was designed in the range of $20 \mathrm{kr} / \mathrm{min}$. The mount consisted of a "tolerance ring" [22] clamped around the outside of the bearing, and compressed into a bore. The tolerance ring, shown in Fig. 13, is a band of spring steel with ridges that flex to provide compliance.

\section{DYNAMICS AND CONTROL}

\section{A. Machine Model}

The homopolar inductor motor has the same terminal characteristics as a traditional field-wound synchronous machine. Using a two-phase stator model, we have two orthogonal armature windings whose orientations are denoted as axes $a$ and $b$. A field winding along the rotor axis $f$ has mutual inductance with the armature; this inductance varies with the angle $\theta$ between the $a$ and $f$ axes. Thus in a stationary reference frame we have the two-axis model

$$
\frac{d}{d t} \lambda_{a b f}=-\mathbf{R L}^{-1} \lambda_{a b f}+V_{a b f}
$$

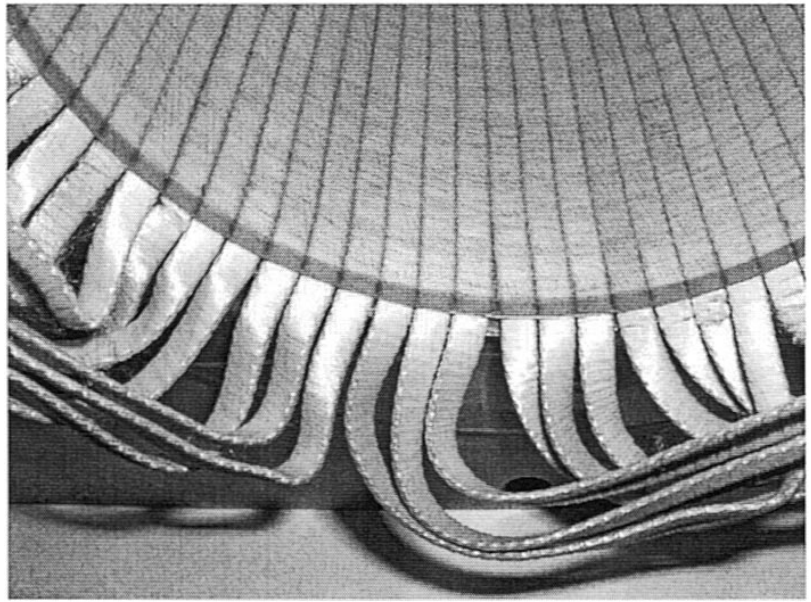

Fig. 12. Close-up view of completed armature winding.

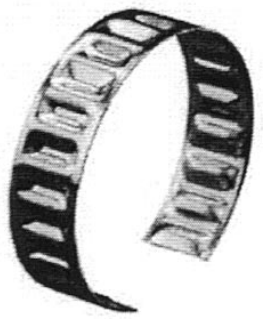

Fig. 13. Tolerance ring used in the compliant bearing mount.

where

$$
\begin{aligned}
\mathbf{R} & =\left[\begin{array}{ccc}
R & 0 & 0 \\
0 & R & 0 \\
0 & 0 & R_{f}
\end{array}\right] \\
\mathbf{L} & =\left[\begin{array}{ccc}
L & 0 & L_{m} \cos \theta \\
0 & L & -L_{m} \sin \theta \\
L_{m} \cos \theta & -L_{m} \sin \theta & L_{f}
\end{array}\right] .
\end{aligned}
$$

The mechanical frequency of the rotor is governed by

$$
\frac{d}{d t} \omega_{m}=-\frac{B}{J} \omega_{m}+\frac{1}{J} \tau_{e}
$$

where $J$ is the inertia of the rotor, $B$ represents linear drag, and $\tau_{e}$ is electrical torque given by

$$
\tau_{e}=\frac{d}{d \theta} \frac{1}{2} \lambda^{T} \mathbf{L}^{-1} \lambda
$$

It is advantageous to transform the equations into a synchronous reference frame, which we denote with axes $d, q$. The natural choice of input for our six-step drive scheme is the inverter electrical frequency $\omega_{e}$, and we choose to orient the $q$ axis with the armature voltage vector. As a consequence, $V_{q}$ is constant, and $V_{d}$ is identically zero. A high-bandwidth current control loop is implemented to set $i_{f}$, allowing the dynamics of $\lambda_{f}$ to drop out of the model. Under these conditions, the electrical dynamics simplify to

$$
\frac{d}{d t} \lambda_{d}=-\frac{R}{L} \lambda_{d}+\omega_{e} \lambda_{q}+\frac{R L_{m}}{L} i_{f} \cos \theta
$$




$$
\begin{aligned}
\frac{d}{d t} \lambda_{q} & =-\omega_{e} \lambda_{d}-\frac{R}{L} \lambda_{q}-\frac{R L_{m}}{L} i_{f} \sin \theta+V_{q} \\
\frac{d}{d t} \theta & =\omega_{e}-4 \omega_{m}
\end{aligned}
$$

where (9) describes the evolution of the angle, $\theta$, between the reference frame and the rotor. Finally, we are interested in the outputs $i_{d}$ and $i_{q}$

$$
\begin{aligned}
i_{d} & =\frac{1}{L} \lambda_{d}-\frac{L_{m}}{L} i_{f} \cos \theta \\
i_{q} & =\frac{1}{L} \lambda_{q}+\frac{L_{m}}{L} i_{f} \sin \theta .
\end{aligned}
$$

Since the principle function of the flywheel energy storage system is as an electrical energy reservoir, we wish to control the flow of electrical power into and out of the machine rather than a mechanical quantity such as torque or speed. Our strategy for this is to focus on the electrical variables, developing instantaneous control of electrical power flow, considering the speed to vary slowly. The effect of extracting or supplying power to the machine is to decelerate or accelerate the rotor, respectively. Explicitly, real power is controlled by regulating $i_{q}$, while reactive power is controlled by regulating $i_{d}$.

For consideration of the electrical power flow dynamics, we treat the speed as a constant parameter. A more formal analysis would rely on singular perturbation theory with speed and other mechanical variables treated as forming the "slow subsystem." We omit the details here- a general treatment can be found in [23]. Holding $w_{m}$ constant and performing a small signal linearization of the electrical subsystem about a desired operating point, we obtain a linear state-space model for the electrical subsystem. We then compute the transfer function matrix $H(s)$, partitioned as

$$
\left[\begin{array}{l}
i_{d}(s) \\
i_{q}(s)
\end{array}\right]=\left[\begin{array}{ll}
H_{11} & H_{12} \\
H_{21} & H_{22}
\end{array}\right]\left[\begin{array}{l}
i_{f}(s) \\
\omega_{e}(s)
\end{array}\right]
$$

where the functions $H_{11}, H_{12}, H_{21}$, and $H_{22}$ are given by (13)-(16). See (13)-(17) at the bottom of the page.

Bode plots of these functions are shown in Fig. 14. Table III gives the operating point values used to generate the plots. Note that at low frequencies the magnitude of the diagonal terms is larger than that of the off-diagonal terms. Although for clarity
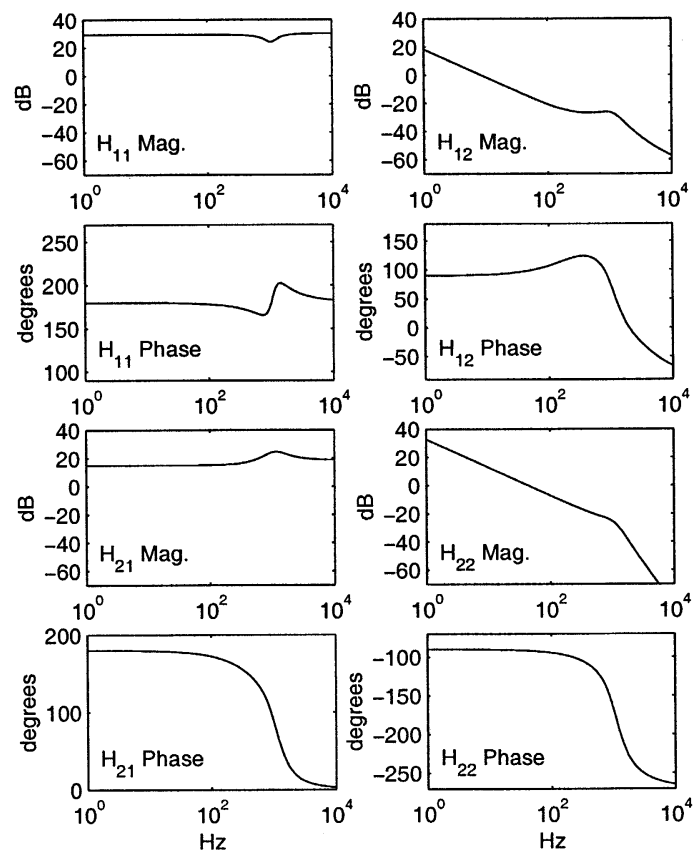

Fig. 14. Bode plots for the homopolar inductor motor.

TABLE III

SMALL-Signal OPERATING POINT

\begin{tabular}{c|c}
\hline$V$ & $70 \mathrm{~V}$ \\
$\theta$ & $15^{\circ}$ \\
$\omega_{e}$ & $6283 \mathrm{rad} / \mathrm{s}$ \\
$i_{d}$ & $0 \mathrm{~A}$ \\
$i_{q}$ & $80 \mathrm{~A}$ \\
$i_{f}$ & $9.29 \mathrm{~A}$ \\
$\lambda_{d}$ & $9.9 \times 10^{-3} \mathrm{~Wb}$ \\
$\lambda_{q}$ & $0 \mathrm{~Wb}$ \\
\hline
\end{tabular}

we only plot results for one operating point, the qualitative relationship among the magnitudes of the four terms holds over a wide range of operating points. This carries important consequences for our control, as discussed in Section III-B.

\section{B. Control Design}

The objective in designing a controller is to stabilize the system for operating points near unity power factor, and to

$$
\begin{aligned}
H_{11} & =-\left(\frac{L_{m}}{L} \cos \theta\right) \frac{s^{2}+\frac{R}{L} s+\omega_{e}^{2}+\omega_{e} \frac{R}{L} \tan \theta}{D} \\
H_{21} & =\left(\frac{L_{m}}{L} \sin \theta\right) \frac{s^{2}+\frac{R}{L} s+\omega_{e}^{2}-\omega_{e} \frac{R}{L} \cot \theta}{D} \\
H_{12} & =\frac{\left\{i_{q} s^{2}+\left(\frac{R}{L} i_{q}-\frac{1}{L} \omega_{e} \lambda_{d}\right) s+\omega_{e}^{2}\left(i_{q}-\frac{1}{L} \lambda_{q}\right)+\omega_{e} \frac{R}{L}\left(i_{d}-\frac{1}{L} \lambda_{d}\right)\right\}}{\{s D\}} \\
H_{22} & =\frac{\left\{-i_{d} s^{2}-\left(\frac{R}{L} i_{d}+\frac{1}{L} \omega_{e} \lambda_{q}\right) s-\omega_{e}^{2}\left(i_{d}-\frac{1}{L} \lambda_{d}\right)+\omega_{e} \frac{R}{L}\left(i_{q}-\frac{1}{L} \lambda_{q}\right)\right\}}{\{s D\}} \\
D & =s^{2}+2 \frac{R}{L} s+\left(\frac{R}{L}\right)^{2}+\omega_{e}^{2}
\end{aligned}
$$




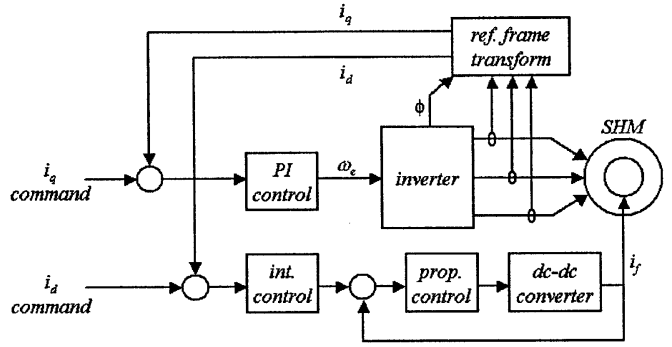

Fig. 15. Control system block diagram.

TABLE IV

CloSED-LOOP POLES

\begin{tabular}{c}
$-2709 \pm 6063 j$ \\
-558.3 \\
-354.9 \\
-76.21 \\
-0.145 \\
\hline
\end{tabular}

be able to track a command for real power. As the excitation voltage is fixed, this amounts to controlling $i_{q}$ to a reference value while keeping $i_{d}$ at zero. Intuition for the operation of the system at or near unity power factor can be gained by examining the phasor diagram in Fig. 7. Note that the figure is not drawn to scale; over the desired range of operating points, the angle $\theta$ will be small, and the effect of resistive drop will be negligible. Letting $\sin (\theta) \cong \theta, i_{q}$ varies nearly linearly with $\theta$ (and hence the integral of $\omega_{e}$ ) with little effect on $i_{d}$. Similarly, adjusting the magnitude of the back EMF $E$ controls $i_{d}$ with little effect on $i_{q}$. These are the standard relations for a synchronous generator connected to an infinite bus.

The Bode plots for the linearized system shown in Fig. 14 confirm the intuition of the phasor diagram, and provide insight into the dynamics of the electrical states. It can be shown that for the purposes of the control scheme, the relative magnitudes of the quantities $\left|H_{11} H_{22}\right|$ and $\left|H_{12} H_{21}\right|$ to a large extent determine whether the system can be treated as a pair of decoupled scalar systems [3]. Adding the log magnitudes from the figure, we see that $\left|H_{11} H_{22}\right|$ is greater than $\left|H_{12} H_{21}\right|$ by roughly 30 $\mathrm{dB}$ at low frequencies.

Given the decoupled nature of the system, we can construct two independent control loops, as shown in the block diagram in Fig. 15. An integral control law for the $i_{d} \rightarrow i_{f}$ loop ensures that the power factor is driven to unity. A PI control on the $i_{q} \rightarrow \omega_{e}$ loop provides the desired response for tracking the commanded active current. Table IV, showing the resulting closed-loop poles for the linearized system, confirms that the control indeed stabilizes the system at the desired operating point.

An attractive feature of the control scheme is its simplicity. Unlike flux-oriented schemes, the controller does not require an observer to resolve the reference frame. The reference frame angle $\phi$ is defined by the inverter voltage, therefore the angular orientation of the reference frame with respect to the stator is known explicitly from the commanded voltage. The sampling and control loops are triggered synchronously with the inverter switching. Furthermore, because the magnitude of the excitation voltage is fixed, it is only necessary to sample the armature currents. Note that while field current is also sampled to
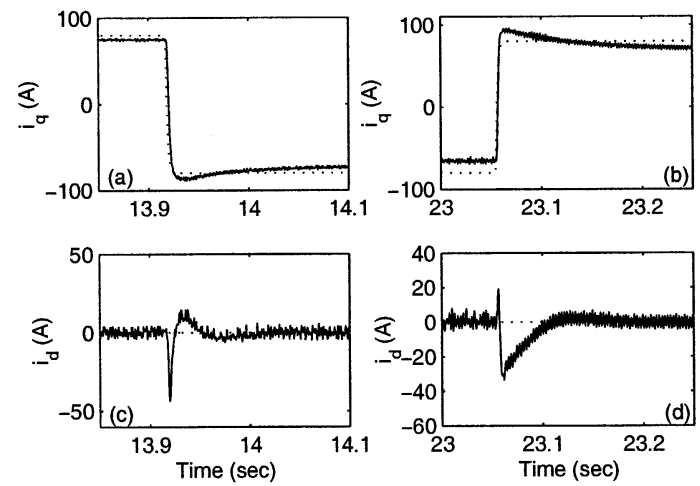

Fig. 16. Experimental step response, command (dotted) and output (solid). Plots (a) and (c) show $i_{q}$ and $i_{d}$ response to a $+80 \mathrm{~A}$ to $-80 \mathrm{~A}$ command of $i_{q}$. Plots (b) and (d) show response to a $-80 \mathrm{~A}$ to $+80 \mathrm{~A}$ command.

implement a separate current control loop, this sampling is not fundamentally necessary for the overall control scheme-it is a design choice to simplify the experimental setup. The inverter switching and the generation of a sampling interrupt are both handled by an FPGA. Samples of $i_{d}$ and $i_{q}$ are taken just before inverter switching occurs, so that the orientation of the current relative to inverter voltage is known. Note that this means sampling occurs at a rate of six times the electrical frequency. These samples, rotated into the synchronous reference frame, are then made available to the control loop, which performs control calculations at a fixed rate of $1.5 \mathrm{kHz}$.

\section{Controller Simulation and Experimental Results}

Fig. 16 shows system response to step commands in $i_{q}$ from $80 \mathrm{~A}$ to $-80 \mathrm{~A}$, and $-80 \mathrm{~A}$ to $80 \mathrm{~A}$, while $i_{d}$ is commanded to a constant zero. The plots show experimental results and the current commands. Fig. 22 shows the inverter frequency corresponding to this power trajectory, and demonstrates the controller's capability to execute constant current accelerations and decelerations.

\section{EXPERIMENTAL RESULTS}

The first experimental goal was to determine the machine parameters of the prototype and compare them to the designed values. For the purposes of the controller, it can be seen that the primary motor parameters needed for the machine model described in Section III-A are $L, L_{m}, R_{a}$, and $J$. Additional parameters needed to model the losses in the motor include $R_{f}$, bearing loss coefficients, inverter loss coefficients, and core loss coefficients. The dc resistances were measured directly, but most of these parameters were determined by fitting models to experimental measurements. A summary of the designed and measured values for these parameters is shown in Table V. All experimental data was obtained using discrete inductors in series with the motor phases to increase the machine inductance $L$ to the desired value of $33 \mu \mathrm{H}$. All tests were conducted under a moderate vacuum of roughly $500 \mathrm{~Pa}$.

\section{A. Core Loss and Harmonic Loss Measurements}

Two methods were used to measure the core loss. The first method was to spin the flywheel at a constant speed and measure 
TABLE V

SIMULATION PARAMETERS

\begin{tabular}{l|l|l}
\hline Description & $\begin{array}{l}\text { Design } \\
\text { Value }\end{array}$ & $\begin{array}{l}\text { Measured } \\
\text { Value }\end{array}$ \\
\hline Armature Inductance $L$ & $33 \mu \mathrm{H}$ & $33 \mu \mathrm{H}$ \\
Mutual inductance $L_{m}$ & $1.1 \mathrm{mH}$ & $1.0 \mathrm{mH}$ \\
Residual flux $\lambda_{r}$ & $\mathrm{NA}$ & $0.0018 \mathrm{~Wb}$ \\
Armature resistance $R_{a}$ & $42.0 \mathrm{~m} \Omega$ & $45.4 \mathrm{~m} \Omega$ \\
Field resistance $R_{f}$ & $3.22 \Omega$ & $3.44 \Omega$ \\
Moment of inertia $J$ & $0.123 \mathrm{~kg} \cdot \mathrm{m}^{2}$ & $0.134 \mathrm{~kg} \cdot \mathrm{m}^{2}$ \\
\hline
\end{tabular}

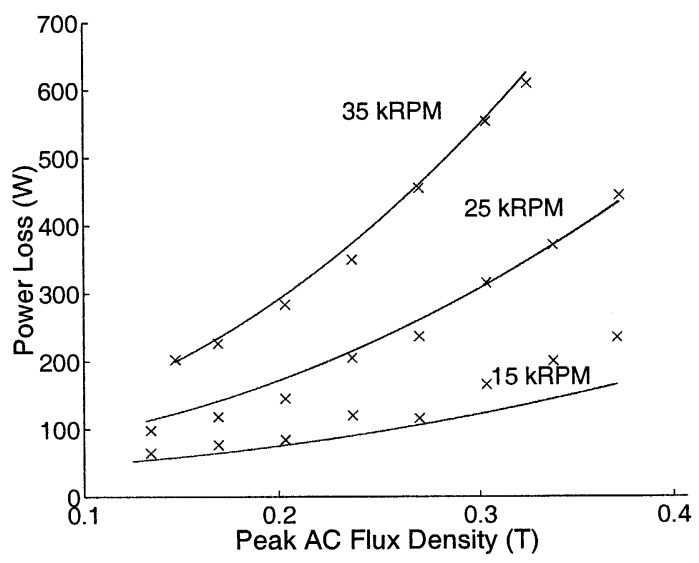

Fig. 17. Plot of constant-speed core loss tests versus peak ac flux density for various speeds. A subset of the measurements used to generate the parameters for the model is indicated by the x's, and the solid line represents the fitted model.

the input power needed to keep the flywheel spinning. Since there is no net mechanical change in energy, the input power is equal to the losses in the system. In these "constant-speed" tests, the losses are the sum of the following:

1) aerodynamic drag;

2) bearing drag;

3) stator core loss;

4) conduction loss of the fundamental current;

5) inverter switching loss;

6) rotor time harmonic loss;

7) stator harmonic current conduction loss.

Of these loss components, the stator core loss and rotor time harmonic losses dominate. The results of these constant-speed tests are shown in Fig. 17. The peak ac flux density is the amplitude of the maximum flux variation in the stator. For example, a peak flux density of $0.8 \mathrm{~T}$ with a minimum flux density of 0.2 $\mathrm{T}$ would imply a peak ac flux density of $0.3 \mathrm{~T}$. A model for the bearing and core loss components was assumed, and parameters were fit to this data.

The second method for measuring the core loss was to maintain a constant flux level with the field winding, and then let the flywheel spin down with the inverter disabled. By using the rotor's moment of inertia, the losses can be calculated by measuring the rate at which the rotor spins down. In these "spindown" tests, no current flows through the armature and the inverter is not switched, therefore the only losses are as follows:

1) aerodynamic drag;

2) bearing drag;

3) stator core loss.

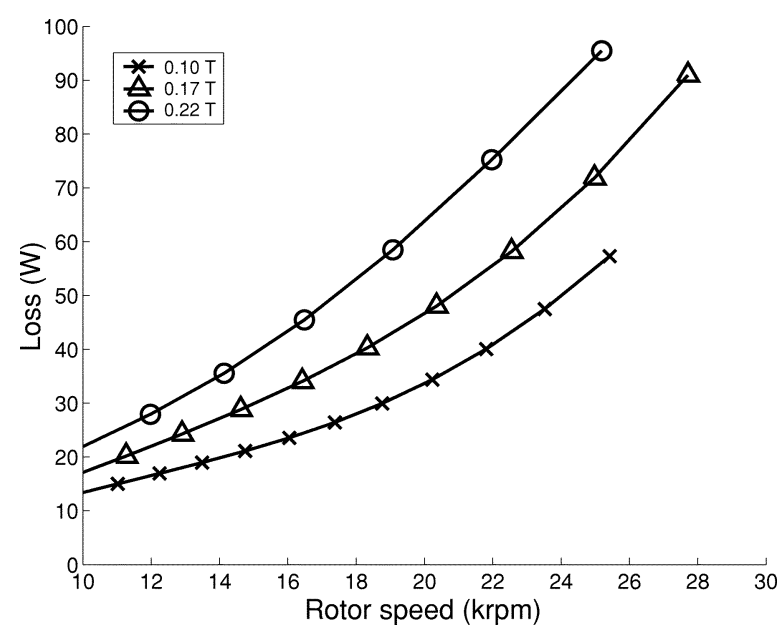

Fig. 18. Plot of spin-down core loss test results versus speed for three peak ac flux density levels.

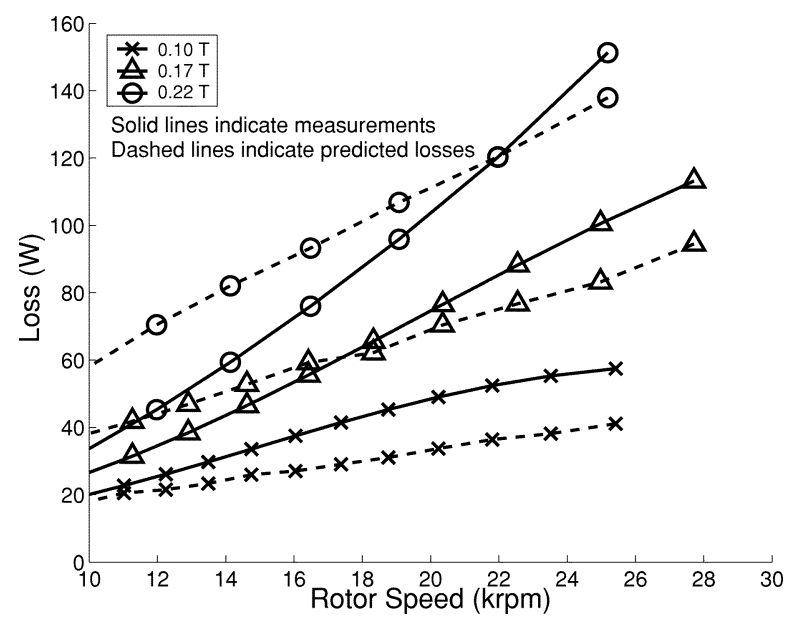

Fig. 19. Plot of inverter and harmonic losses. Measured losses (solid line) are calculated from the results of Figs. 17 and 18. Predicted losses calculated analytically are indicated with the dashed lines. The flux levels are indicated by the circles, triangles, and x's, which correspond to the legend in Fig. 18.

Once again, in the spin-down tests the stator core loss is the dominant loss component. The results of the spindown tests are plotted in Fig. 18. The measured stator core loss was larger than the predictions used in the design by as much as a factor of four in the range of the data shown in Fig. 18. The chief difference is that the measured core loss grew at rate proportional to $\omega_{e}^{2}$, whereas the manufacturer data sheet predicted growth proportional to $\omega_{e}^{1.4}$. This suggests that there may be an additional aspect of the stator core loss that was not modeled in the design. We note that the design is not core loss dominated, so the impact on efficiency is not extreme.

In addition to calculating the stator core loss, the results from the constant-speed and spin-down tests can also be used to calculate the harmonic loss components. Calculating the difference between the constant-speed tests and the spin-down tests reveals the sum of loss components 4-7 of the constant-speed tests. Fig. 19 plots the difference between the fitted model generated from the constant-speed tests and the results of the spin-down tests. These curves (solid line) are compared to results of the analytical calculations of loss components 4-7 (dashed line). 


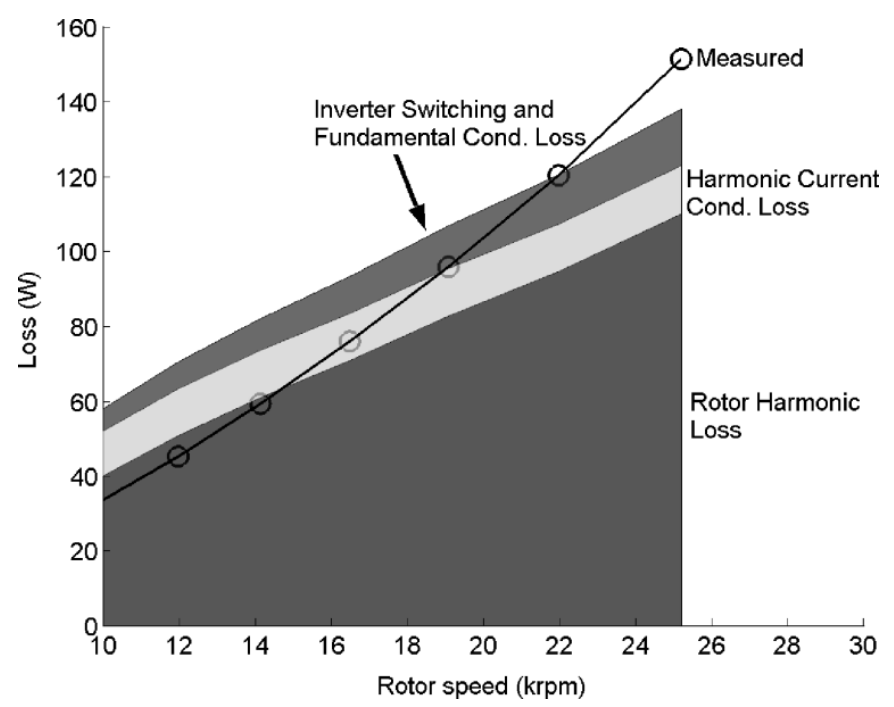

Fig. 20. Breakdown of predicted harmonic and inverter losses compared to measurements. The solid line is the same as the 0.22-T line in Fig. 19, and the shaded areas represent the components of the predicted loss for this test.

A breakdown of the losses for the $0.22 \mathrm{~T}$ test in Fig. 19 is shown in Fig. 20, which compares the measured to the predicted losses. The predicted inverter switching losses are based on manufacturer data, and the harmonic current and rotor harmonic losses are calculated using the methods described in the Appendixes A and B. The figure shows that the dominant losses are the rotor harmonic losses, and that the analytical methods provide a reasonable calculation for these losses.

The agreement between the measured and predicted rotor harmonic losses also confirms that low rotor losses have been achieved. As mentioned in Section II-A, low rotor loss is one of the most important and difficult requirements to meet in a flywheel energy storage system. Meeting this design goal demonstrates that a high-speed homopolar inductor motor with a solidsteel rotor can have low rotor losses even while running under six-step excitation.

\section{B. Performance Results}

The system efficiency was measured by cycling power into and out of the flywheel over a 2:1 speed range. Fig. 21 shows an examples of the phase current and voltage during one of these tests. Data from an efficiency test consisting of accelerations and decelerations between 30000 and $60000 \mathrm{r} / \mathrm{min}$ while charging and subsequently discharging electrical power at a 9.4-kW power level is shown in Fig. 22. The electrical power is shown in the top graph, the rotor speed profile in the second, and the measured efficiency in the bottom graph. Since the starting and ending rotor speeds for the test are identical, the net mechanical power during the test is zero. Therefore, the integral of electrical power $P_{e}$ over the test is equal to the loss, and the average efficiency over the entire test can be calculated as

$$
\eta_{\mathrm{avg}}=1-\frac{\int_{0}^{T} P_{e} d t}{\int_{0}^{T}\left|P_{e}\right| d t} .
$$

The advantage of using the above expression for $\eta_{\text {avg }}$ is that it can be calculated directly and accurately from voltage and
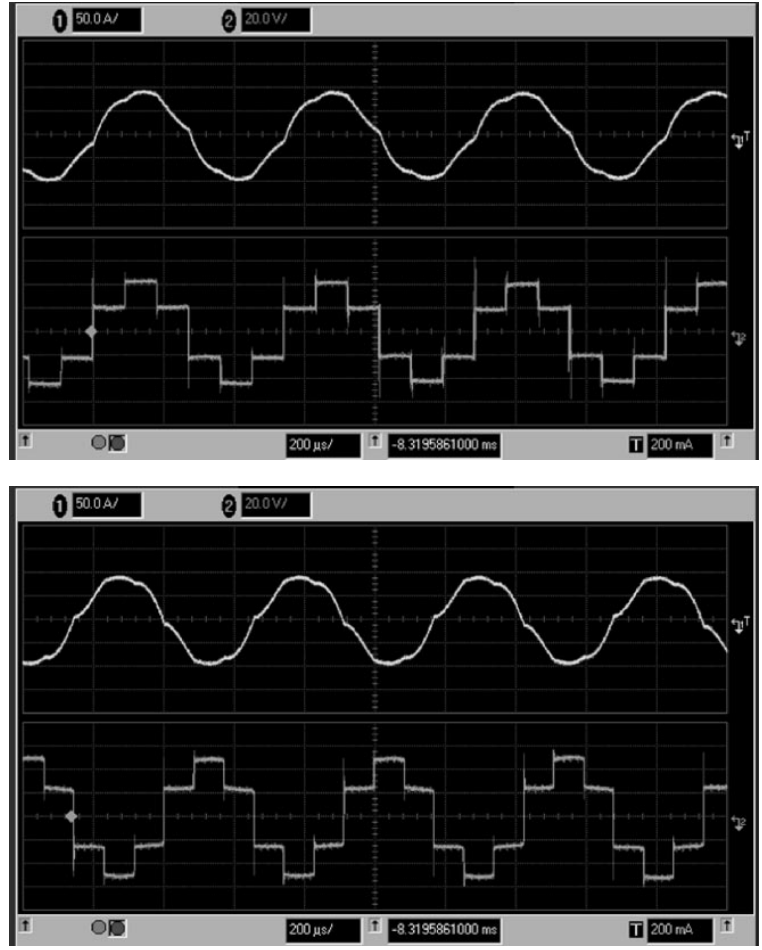

Fig. 21. Oscilloscope traces of phase current (upper traces) and line-to-neutral voltage (lower traces) at $28 \mathrm{kr} / \mathrm{min}$ during a 90-A 45-V 6-kW charge (upper photograph) and discharge (lower photograph).

current measurements of the dc bus, and it includes all the losses that occur in the entire system, i.e., the inverter, the field winding $\mathrm{dc}-\mathrm{dc}$ converter, and the motor/generator. The average efficiency for this particular test and other tests run between 15-30 kr/min and 30-60 kr/min is shown in Fig. 24.

Although the above measurements reveal the average efficiency of the flywheel during the test, they do not reveal the efficiencies at any single operating point. To calculate the efficiency for a trajectory as shown in the bottom graph of Fig. 22, it was necessary to use the rotor inertia $J$ and these expressions for mechanical power and efficiency

$$
\begin{aligned}
P_{m} & =J \omega_{m} \dot{\omega}_{m} \\
\eta & =1-\frac{P_{e}-P_{m}}{\left|P_{e}\right|}
\end{aligned}
$$

to calculate the efficiency for each point in time of the test. A 0.3 -s-long moving time average was applied to the efficiency data in the bottom plot of Fig. 22.

A breakdown of the loss components was calculated using the core loss model developed from the core loss tests and the harmonic loss equations. A plot of the loss breakdown for one cycle of the efficiency test is shown in Fig. 23, and Table VI summarizes the data for this particular test. From the figure, it can be seen that the loss model provides a good fit to the data. The armature conduction loss is the largest portion of the loss at $53.3 \%$, followed by the core loss at $30.0 \%$, and the field winding conduction loss at $13.4 \%$. Notably, the rotor losses are less than $50 \mathrm{~W}$, and the total harmonic losses contribute less than $4 \%$ of the total loss. For clarity, in this breakdown the inverter losses are included in the armature conduction loss, and the dc/dc converter losses are included in the field winding conduction losses. 


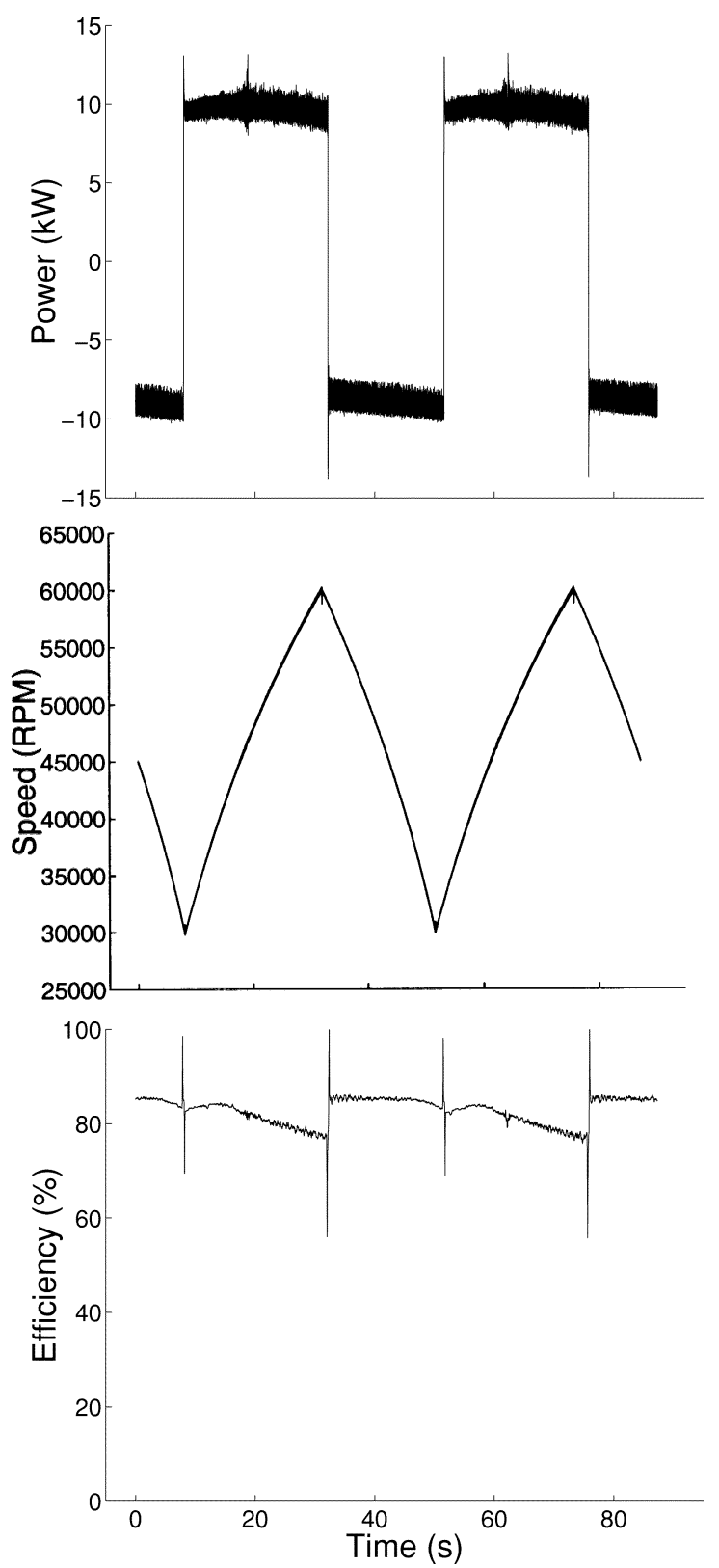

Fig. 22. Plots of flywheel system input power, rotor speed, and system efficiency versus time during a $9.4-\mathrm{kW} 15-30-\mathrm{kr} / \mathrm{min}$ efficiency test.

Fig. 24 plots the measured efficiency for several power levels over the $15-30-\mathrm{kr} / \mathrm{min}$ and $30-60-\mathrm{kr} / \mathrm{min}$ speed ranges, conducted with voltages $V$ of 50 and $100 \mathrm{~V}$, respectively. Also plotted are results from the loss model fitted to the data. An average efficiency of $83 \%$ was achieved at $9.4 \mathrm{~kW}$ over the $30-60-\mathrm{kr} / \mathrm{min}$ speed range.

\section{Analysis of Results}

By comparing the fitted loss model to our optimization model, it can be seen that there are several reasons why the measured efficiencies are lower than those predicted by the model used in the optimization. In order of importance, they were as follows.

1) Armature resistance was $80 \%$ higher than the measured DC value at room temperature. This was due to an unexpectedly high temperature rise in the windings, and was

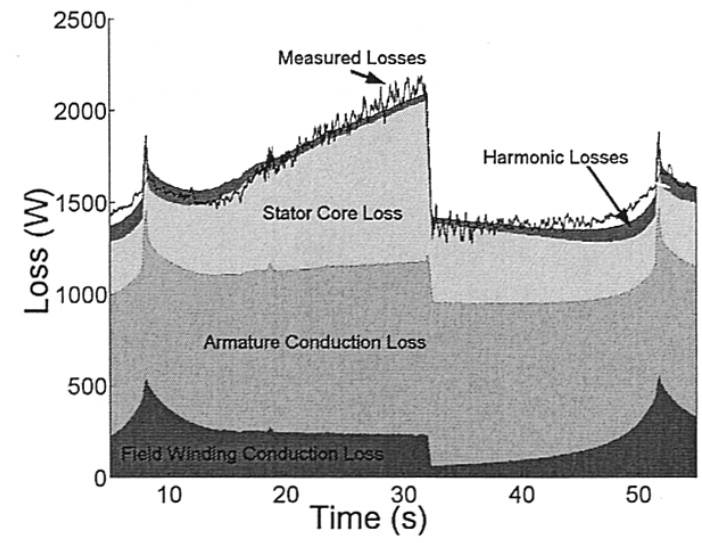

Fig. 23. Loss breakdown for $9.4-\mathrm{kW} 30-60-\mathrm{kr} / \mathrm{min}$ efficiency test. The solid line indicates the total measured loss, and the shaded areas indicate the various loss components (rotor harmonic and current harmonic conduction losses are grouped together as "harmonic losses").

TABLE VI

EFFICIENCY TEST DATA

\begin{tabular}{c|c}
\hline Average Power $\left|P_{e}\right|$ & $9.4 \mathrm{~kW}$ \\
Speed Range & $30 \mathrm{krpm}-60 \mathrm{krpm}$ \\
Average Eff. & $82.8 \%$ \\
\hline
\end{tabular}

Loss Breakdown from Fitted Model

(as percentage of total measured loss)

\begin{tabular}{c|c} 
Armature Cond. & $53.3 \%$ \\
Field Wind. Cond. & $13.4 \%$ \\
Stator Core Loss & $30.0 \%$ \\
Rotor Harm. Loss & $3.1 \%$ \\
Harm. Curr. Cond. & $0.2 \%$ \\
\hline Total & $99.8 \%$ \\
\hline
\end{tabular}

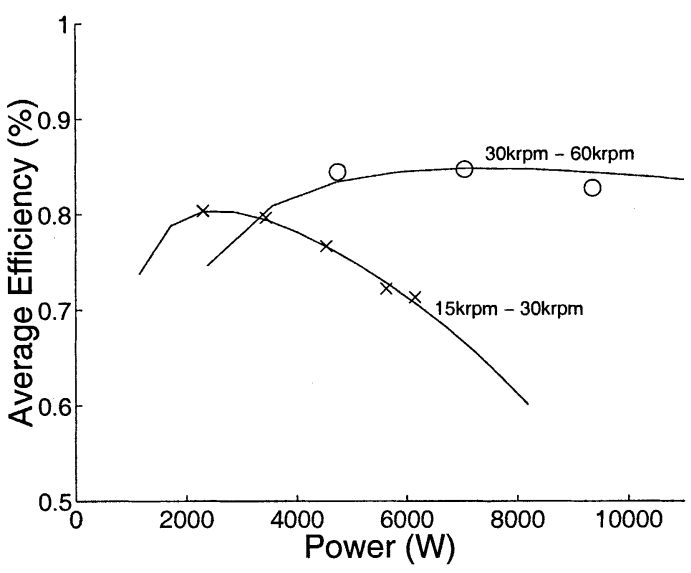

Fig. 24. Measured average efficiencies $\eta_{\text {avg }}$ for $15-30-\mathrm{kr} / \mathrm{min}$ tests (x's)and $30-60-\mathrm{kr} / \mathrm{min}$ tests (o's). Solid lines indicate results from the fitted model.

confirmed by resistance measurements taken while the armature was hot.

2) The motor was not running at its designed operating point at higher speeds. The efficiency graph at the bottom of Fig. 22 reveals that the efficiency dropped during charging as the flywheel speeds up. This was unexpected, because the design calculations predicted that efficiency would stay relatively constant over the entire speed range. The cause was a phase delay in the sampling from an analog filter used to process the current 
measurements. The result of the phase delay was such that at speeds above $40 \mathrm{kr} / \mathrm{min}$, instead of running at unity power factor, the flywheel would run at a leading power factor while charging, and a lagging power factor while discharging. This caused extra core loss, field winding conduction loss, and reduced the power output for a given armature current during charging.

3) The mutual inductance $L_{m}$ gradually dropped by as much as $30 \%$ as the field winding current was increased. This indicated that saturation was occurring at lower flux densities than expected. The exact reason for this is unclear, though it may be that the midsection of the stator back iron near the field winding began to saturate and increased the reluctance of the magnetic path.

4) The core loss grew at a higher rate with respect to frequency than predicted.

To improve the performance in future designs, the optimization process should incorporate the conduction, core loss, and harmonic loss models generated from the experimental data.

\section{CONCLUSION}

The design and experimental results from an integrated flywheel energy storage system have been presented. The advantages of a slotless homopolar inductor motor for high-speed applications are described. An analytical calculation and experimental results show that low rotor losses can be achieved with a solid steel rotor.

A sensorless control scheme that does not require an estimator for rotor position or flux was presented. The controller is implemented as part of a six-step inverter drive strategy that maintains high efficiency while operating at unity power factor. A strategy for adjusting the armature inductance to reduce rotor losses due to the six-step harmonics is described in Appendix C. The controller was demonstrated for speeds from 3000 to $60000 \mathrm{r} / \mathrm{min}$.

Experimental results of the system efficiency were presented. An average efficiency of $83 \%$ was achieved at $9 \mathrm{~kW}$ over the $30-60-\mathrm{kr} / \mathrm{min}$ speed range. Extrapolating the loss model fit to this data predicts that $88 \%$ efficiency could be achieved for a $30-\mathrm{kW} 50-100-\mathrm{kr} / \mathrm{min}$ test.

\section{APPENDIX}

These Appendixes present the methods used to calculate losses arising from time harmonics generated by a six-step drive and winding spatial harmonics. The harmonic losses that are of the most concern are those due to eddy currents flowing in the solid-steel rotor which are generated when the rotor sees a time-varying flux generated from either harmonic currents or spatial effects.

The time harmonics in this motor arise from the switching of the inverter. Since six-step drive is applied, the harmonics are of a relatively low frequency, occurring at integral multiples of $6 w_{e}$ (six times the fundamental electrical frequency) in the rotor frame. The harmonic currents from this switching cause additional armature conduction loss, rotor loss, and stator core loss. Calculations for the armature harmonic conduction and rotor harmonic loss are presented in Appendixes A and B; the stator core harmonic loss can be analyzed using standard core loss methods based on manufacturers data for the core material.
TABLE VII

HARMONIC LOSSES FOR PROTOTYPE DESIGN

\begin{tabular}{l|l}
\hline Parameter & $\begin{array}{l}\text { Prototype } \\
\text { Value }\end{array}$ \\
\hline $\begin{array}{l}\text { Motor and drive Parameters } \\
L\end{array}$ & $33 \mu \mathrm{H}$ \\
Voltage fundamental $V$ & $100 \mathrm{~V}$ \\
$\quad$ Phase current $I_{a}$ & $66 \mathrm{~A}$ \\
$\quad$ Speed range $\omega_{m}$ & $30 \mathrm{krpm}-60 \mathrm{krpm}$ \\
$\quad$ Corresponding elec. freq. $\omega_{e}$ & $2.0 \mathrm{kHz}-4.0 \mathrm{kHz}$ \\
Worst-case harmonic losses & \\
$\quad$ (at 9.4kW, 30 krpm) & \\
$\quad$ Stator Harm. Curr. Cond. Loss & $7.9 \mathrm{~W}$ \\
$\quad$ Rotor Time Harmonic Loss & $100 \mathrm{~W}$ \\
$\quad$ Rotor Spatial Harmonic Loss & $<1.0 \mathrm{~W}$ \\
Average harmonic losses & \\
$\quad$ (9.4 kW, 30 krpm-60 krpm) & \\
Stator Harm. Curr. Cond. Loss & $3.0 \mathrm{~W}$ \\
Rotor Time Harmonic Loss & $50.8 \mathrm{~W}$ \\
$\quad$ Rotor Spatial Harmonic Loss & $<1.0 \mathrm{~W}$ \\
\hline
\end{tabular}

The magnitude of the harmonic losses from time-varying currents can be controlled by adjusting the armature inductance $L$. Increasing $L$ either by changing the winding design or adding external inductors reduces the harmonic losses, however it also reduces the achievable motor power factor when operating at inverter unity power factor, and impacts overall efficiency. Design criteria for sizing $L$ to achieve a minimum machine power factor over a certain operating range is presented in Appendix C.

The slotless stator in this motor eliminates slot harmonics, therefore the only source of spatial harmonics is the trapezoidal winding distribution. The losses from the trapezoidal winding distribution are discussed in Appendix D.

Table VII summarizes the calculations for the harmonic losses of the prototype during one of the experiments. Indicated in the table are the worst-case losses and average losses for each harmonic loss component for the 9.4-kW 30-60-kr/min test.

\section{APPENDIX A}

\section{StATOR HARMONIC CURRENT CONDUCTION LOSS}

The voltage on phase $a$ of a three-phase motor driven with a six-step excitation at an electrical frequency $\omega_{e}$ can be expressed as a sum of its Fourier components

$$
V_{a}=V \sum_{k=1,5,7,11,13 \ldots} A_{k} \cos \left(k \omega_{e} t+\frac{\pi}{2}\right)
$$

where $V=4 / \pi\left(V_{\text {bus }} / 2\right)$ is the amplitude of the stator voltage and $A_{k}=1 / k$ is the coefficient for each harmonic component. Triple-n harmonics are excluded by the three-phase connection of the motor. Phase voltages $V_{b}$ and $V_{c}$ have analogous expressions shifted by $+2 \pi k / 3$ and $-2 \pi k / 3$, respectively. Neglecting resistance, the expression for the phase currents is then

$$
\begin{array}{r}
I_{a}=V\left(\sum_{k=1,5,7,11,13 \ldots} \frac{A_{k}}{k \cdot \omega_{e} \cdot L} \cos \left(k \omega_{e} t\right)\right) \\
-\frac{E}{\omega_{e} \cdot L} \cos \left(\omega_{e} t\right)
\end{array}
$$


where $L$ is the phase inductance, and $E$ the back EMF as a complex vector.

The back EMF only has a fundamental component, therefore the additional conduction in phase $a$ for the harmonic currents is then

$$
\begin{aligned}
P_{a}= & \sum_{k} \frac{1}{2} I_{a k}^{2} R \\
= & \sum_{k} \frac{1}{2} V^{2}\left(\frac{A_{k}}{k \cdot \omega_{e} \cdot L} \cos \left(k \omega_{e} t\right)\right)^{2} R, \\
& \quad \text { for } k=5,7,11,13, \ldots
\end{aligned}
$$

As is evident from (23), increasing $L$ decreases the amplitude of the harmonic currents and thus the associated losses. The additional conduction losses expressed as a fraction of the peak conduction losses is

$$
\frac{P_{a}}{P_{\text {fund }}} \approx \frac{I_{a 5}^{2}+I_{a 7}^{2}+\cdots}{I_{a 1}^{2}}
$$

where $I_{a n}$ is the amplitude of the $n$th harmonic current in phase $a$, and $I_{a 1}$ is the peak fundamental current in phase $a$. The harmonic currents are present whenever the six-step voltage is applied, and the highest losses occur at the lowest speeds. For the example shown in Table VII, the worst case losses represent less than $2 \%$ of the armature losses, and $0.1 \%$ of the total output power.

\section{APPENDIX B \\ ROTOR TIME HARMONIC LOSS ANALYSIS}

Since the rotor is constructed out of a single piece of solid steel, any varying flux imposed by either time or spatial harmonics will cause rotor loss and subsequent heating. Thus, care must be taken to ensure that the choice of six-step drive does not cause high rotor losses. The primary flux imposed on the rotor is the dc flux imposed by the field winding. The only time varying fluxes seen by the rotor rotating at synchronous speed are time harmonics from currents and spatial harmonics from winding geometry. The following analysis suggests that losses imposed by the current harmonics and spatial harmonics are small.

Expressing the phase currents $I_{a}, I_{b}$, and $I_{c}$ in terms of their Fourier components as is done in (22), and applying the Park transform [24] into the synchronous frame leads to

$$
\begin{aligned}
I_{d}=\frac{V}{\omega_{e} \cdot L} & \left(\sum_{i=1,2,3 \ldots}\left(\frac{A_{6 i-1}}{6 i-1}+\frac{A_{6 i+1}}{6 i+1}\right) \cos \left(6 i \omega_{e} t\right)\right) \\
I_{q}=\frac{V}{\omega_{e} \cdot L} & \left(\left(1-\frac{E}{V_{S}}\right)+\sum_{i=1,2,3 \ldots}\left(-\frac{A_{6 i-1}}{6 i-1}+\frac{A_{6 i+1}}{6 i+1}\right)\right. \\
& \left.\times \sin \left(6 i \omega_{e} t\right)\right) .
\end{aligned}
$$

Examination of these results shows that the rotor sees the flux due to the 5th harmonic current as a backward-rotating flux wave shifted to the 6th harmonic frequency, and the 7th harmonic flux as a forward-rotating flux wave also shifted to the 6th harmonic frequency. Since the rotor core losses are eddy-current dominated at the frequencies of interest, linearity implies that the losses for each harmonic component can be analyzed individually. The losses can then be estimated by analyzing the case of a traveling wave of the appropriate amplitude impinging on a solid steel sheet.

An analytical expression for the losses has been derived in [25] based on transfer function relations found in [26]. The result is

$$
\begin{aligned}
K_{k} & =\frac{I_{k}}{w} \\
P_{\text {loss }} & =\frac{S\left|K_{k}\right|^{2} h w_{e} \mu_{0}^{2}}{\delta_{h} \mu\left[\left(b \sinh b g+\frac{\mu_{0}}{\mu} \cosh b g\right)^{2}+\left(\frac{\mu_{0}}{\mu} \frac{1}{\delta_{h}} \cosh b g\right)^{2}\right]} \\
b & =\frac{m}{r}
\end{aligned}
$$

where $K_{k}$ is the linear current density in $A / m$ along the inner bore of the stator, $I_{k}$ is the amplitude of the current harmonic, $w$ is the width of the armature wire, $S$ is the surface area, $\delta_{h}$ is the skin depth for the material at frequency $w_{e}, r$ is the rotor radius, $g$ is the gap, and $m$ is the spatial harmonic. Since the skin depth $\delta_{h} \ll g$, the problem can be transformed with good accuracy into rectilinear coordinates. The constant $b$ is a result of the coordinate transformation, and $m=$ (\# of poles $) / 2$.

The results from this expression agree with two-dimensional (2-D) finite-element method (FEM) simulations of the rotor profile conducted at lower frequencies $(1 \mathrm{kHz})$. Accurate FEM simulations at the frequencies of interest in our design $\left(\omega_{e}>2 \pi\right.$. $18 \mathrm{kHz})$ are difficult because the skin depths $(26 \mu \mathrm{m}$ at $18 \mathrm{kHz})$ are very small compared to the air gap $(2.16 \mathrm{~mm})$ and other rotor geometry.

Fig. 25 plots the losses calculated for the 5th, 7th, 11th, and 13th harmonics along with the total loss for all harmonics for the target operating speed range with $V=160 \mathrm{~V}$ and $L=33 \mu \mathrm{H}$. Note that the harmonic losses decrease with increasing speed, and the worst case is $175 \mathrm{~W}$ which occurs at $50000 \mathrm{r} / \mathrm{min}$. The average losses under normal operating cycles would be smaller. A calculation of the rotor's thermal radiation indicates that 175 $\mathrm{W}$ of rotor loss with a stator temperature of $50^{\circ} \mathrm{C}$ would imply a rotor operating temperature of approximately $200^{\circ} \mathrm{C}$, which is reasonable for a solid steel rotor.

\section{APPENDIX C \\ SIZING OF ARMATURE INDUCTANCE $L_{a}$}

As noted in the previous two sections, increasing armature inductance $L$ decreases losses due to the harmonics generated from a six-step drive. However, if running at unity inverter power factor, increasing the armature inductance decreases the machine power factor and the overall efficiency of the machine. One approach to constraining $L$ is to choose a maximum acceptable amplitude for one of the harmonic currents and a minimum machine power factor.

Define $I_{a 5}$ to be the amplitude of the 5th harmonic current (the primary source of harmonic losses), and $\theta_{\mathrm{pf}}$ to be the angle to achieve the machine power factor $\cos \theta_{\mathrm{pf}}$. Then, choose $\beta$ such that satisfying the inequality

$$
I_{a 5}<\beta \cdot I_{a 1}
$$




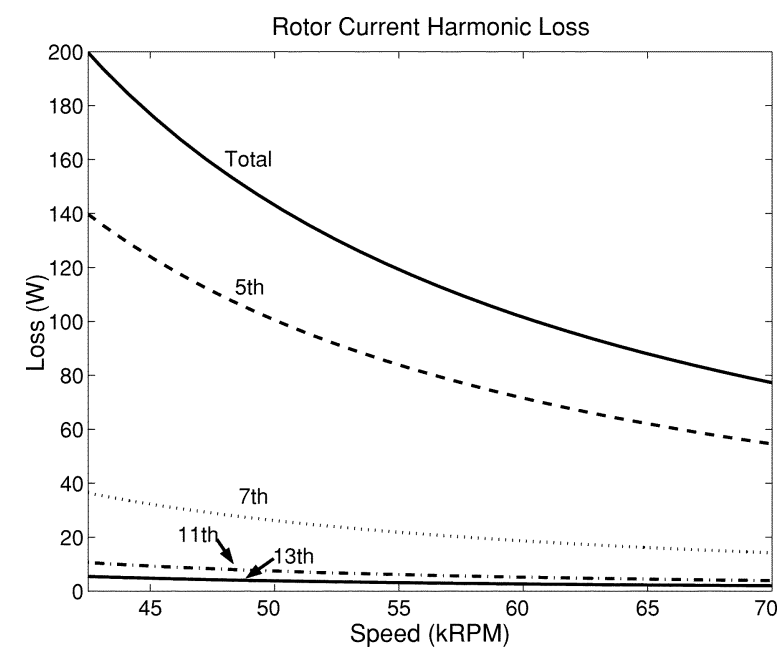

Fig. 25. Rotor core losses due to harmonics.

leads to small enough harmonic currents such that the harmonic conduction and rotor losses are acceptable. Then substituting in the expression for the amplitude of the 5th harmonic component of the current from (22) for $I_{a 5}$ leads to the expression

$$
\frac{1}{\beta \cdot 5^{2}}<\frac{\omega_{e} L I_{a 1}}{V} \text {. }
$$

Now, a constraint for the minimum machine power factor will be developed. From the phasor diagram in Fig. 7, where the inverter is running at unity power factor and the machine power factor angle is $\theta$, the machine power factor will be greater than $\cos \theta_{\mathrm{pf}}$ if

$$
\frac{\left|j \omega_{e} L I_{a 1}\right|}{V}<\tan \theta_{\mathrm{pf}}
$$

Combining (30), (31), and $P=3 / 2 I_{a 1} V$ results in

$$
\frac{1}{\beta \cdot 5^{2}}<\frac{2 \omega_{e} L P}{3 V^{2}}<\tan \theta_{\mathrm{pf}}
$$

This expression helps to guide the choice of $L$ so that the harmonic losses can be limited to some maximum value while a minimum machine power factor at peak power is also maintained. Note that in a six-step drive where $V$ is fixed, the ratio of the maximum speed over minimum speed is constrained by

$$
\frac{\omega_{e, \max }}{\omega_{e, \min }}<\beta \cdot 5^{2} \cdot \tan \theta_{\mathrm{pf}} .
$$

Given the desired 2:1 speed range, and using $\beta=0.12$ (the value used for the example in Table VII), then (33) implies a minimum machine power factor of 0.83 . This minimum machine power factor occurs at full power at $w_{e, \max }$. At full power at $w_{e \text {,min }}$ the machine power factor would be 0.94 . Both cases assume that the inverter is running at unity power factor.

\section{APPENDIX D}

\section{ROTOR SPATIAL HARMONIC LOSS ANALYSIS}

Calculations for the losses associated with spatial winding harmonics ("belt harmonics") can be calculated in a similar fashion to the current harmonic losses. The prototype motor has a trapezoidal winding magnetomotive force (MMF), and the surface current $K_{a}$ of phase $a$ with current $I_{a}$ flowing can also be expressed in terms of its Fourier components as

$$
K_{a}=\frac{I_{a}}{W} \cos \left(\omega_{e} t\right) \sum_{m=1,3,5 \ldots} K_{m} \cos \left(\theta_{s}\right)
$$

where $\theta_{s}$ is the spatial angle along the bore of the motor, $W$ the width of one turn, and $K_{m}$ the amplitude of the $m$ th harmonic. The sum of the surface currents for the three phases is the resultant MMF

$$
K_{\text {tot }}=K_{a}+K_{b}+K_{c} .
$$

It can be shown that when balanced three phase sinusoidal currents $I_{a}, I_{b}$, and $I_{c}$, of equal amplitude $|I|$ are applied and $K_{\text {tot }}$ is expressed in the rotor frame, $K_{\text {tot }}$ can be expressed as a sum of $6 i$ time harmonics [25]

$$
\begin{aligned}
K_{\text {tot }}=\frac{3}{2} \frac{|I|}{W} \times[ & K_{1} \cos \theta_{s} \\
& \left.+\sum_{i=1,2,3 \ldots} K_{6 i-1} \cos \left((6 i-1) \theta_{s}+6 i \omega_{e} t\right)\right) \\
& \left.\left.+\sum_{i=1,2,3 \ldots} K_{6 i+1} \cos \left((6 i+1) \theta_{s}+6 i \omega_{e} t\right)\right)\right] .
\end{aligned}
$$

Since these losses also appear as traveling waves at the 6th harmonic frequency, the losses can be analyzed using (27), with the modification of $b$ such that

$$
b=\frac{m \cdot l}{r}, \quad l=5,7,11,13, \ldots
$$

to reflect the change in the spatial wavelength of the harmonic.

The rotor losses from the winding harmonics are much smaller than the losses from the current harmonics. There are two reasons for this. First, the spatial MMF patterns are trapezoidal for each phase, significantly reducing the 5th and 7th harmonic amplitudes relative to a square-wave MMF pattern. Second, the spatial wavelength for the first winding harmonic induced MMF impinging on the rotor is one-fifth that which corresponds to the fundamental wavelength, resulting in reduced flux penetration into the rotor volume. In the worst case, these losses are estimated at less than $1 \mathrm{~W}$. The above spatial harmonic analysis only considers the losses from spatial harmonics driven by the fundamental current. The losses from spatial harmonics due to temporal harmonic currents (e.g., 5th spatial harmonic with 7th current harmonic) have a negligibly small contribution to the total loss.

\section{ACKNOWLEDGMENT}

The authors would like to thank W. Carlisle, J. Gavazza, and B. Lake of the ERL Machine Shop for their tremendous help in the construction and design of the prototype.

\section{REFERENCES}

[1] P. Tsao, M. Senesky, and S. R. Sanders, "A synchronous homopolar machine for high-speed applications," in Conf. Rec. IEEE-IAS Annu. Meeting, 2002, pp. 406-416.

[2] P. Tsao, "An integrated flywheel energy storage system with homopolar inductor motor/generator and high-frequency drive," $\mathrm{Ph} . \mathrm{D}$. dissertation, Univ. California, Berkeley, CA, 2003. 
[3] M. K. Senesky, "Control of a synchronous homopolar machine for flywheel applications," M.S. thesis, Univ. California, Berkeley, CA, 2003.

[4] (2002) Electrical Energy Storage Systems Applications and Technologies (EESAT) Conf. Proc.. [Online]. Available: www.activepower.com

[5] P. P. Acarnley et al., "An integrated flywheel/machine energy store for road vehicles," Colloq. New Topologies for Permanent Magnet Machines, vol. 1997/090, pp. 9/1-9/6, 1997.

[6] (2002) Electrical Energy Storage Systems Applications and Technologies (EESAT) Conf. Proc.. [Online]. Available: www.pentadyne.com

[7] (2002) Electrical Energy Storage Systems Applications and Technologies (EESAT) Conf. Proc.. [Online]. Available: www.afstrinity.com

[8] (1997) Proc. Int. Telecommunications Energy Conf. (INTELEC). [Online]. Available: www.beaconpower.com

[9] R. Wagner and R. Jansen, "Flywheel technology development at the nasa glenn research center," in Proc. Electrical Energy Storage Systems Applications and Technologies (EESAT), 2002, CD-ROM.

[10] H. Hofmann and S. R. Sanders, "High-speed synchronous reluctance machine with minimized rotor losses," IEEE Trans. Ind. Applicat., vol. 36, pp. 531-539, Mar./Apr. 2000.

[11] M. Hippner and R. G. Harley, "High speed synchronous homopolar and permanent magnet machines comparative study," in Conf. Rec. IEEE-IAS Annu. Meeting, 1992, pp. 74-78.

[12] G. P. Rao, J. L. Kirtley Jr, D. C. Meeker, and K. J. Donegan, "Hybrid permanent magnet/homopolar generator and motor," U.S. Patent 6097 124, Aug. 2000.

[13] O. Ichikawa, A. Chiba, and T. Fukao, "Development of homo-polar type bearingless motors," in Conf. Rec. IEEE-IAS Annu. Meeting, 1999, pp. $1223-1228$

[14] J. He and F. Lin, "A high frequency high power igbt inverter drive for a $45 \mathrm{hp} / 16000 \mathrm{rpm}$ brushless homopolar inductor motor," in Conf. Rec. IEEE-IAS Annu. Meeting, 1995, pp. 9-15.

[15] M. Siegl and V. Kotrba, "Losses and cooling of a high-speed and highoutput power homopolar inductor alternator," in Proc. IEE Int. Conf. Electrical Machines and Drives, Sept. 1991, pp. 295-299.

[16] M. S. Sarma, Electric Machines: Steady-State Theory and Dynamic Performance. New York: West, 1994.

[17] "Metallic materials and elements for aerospace vehicle structures," Dept. Defense, Washington, DC, Rep. MIL-HDBK-5H, 1998.

[18] G. Genta, Kinetic Energy Storage. Boston, MA: Butterworth, 1985.

[19] E. Kramer, Dynamics of Rotors and Foundations. New York: SpringerVerlag, 1993

[20] A. Boglietti, P. Ferraris, M. Lazzari, and F. Profumo, "Energetic behavior of soft magnetic materials in the case of inverter supply," IEEE Trans. Ind. Applicat., vol. 30, pp. 1580-1587, Nov./Dec. 1994.

[21] _ "Energetic behavior of induction motors fed by inverter supply," in Conf. Rec. IEEE-IAS Annu. Meeting, 1993, pp. 331-335.

[22] J. W. Smith, "Tolerance rings," IEEE Ind. Applicat. Mag., vol. 8, pp. 74-82, Sept./Oct. 2002.

[23] P. Kokotovic, H. K. Khalil, and J. O'Reilly, Singular Perturbation Methods in Control. London, U.K.: Academic, 1986.

[24] A. E. Fitzgerald, C. Kingsley, and S. D. Umans, Electric Machinery. New York: McGraw-Hill, 1990.

[25] H. Hofmann, "High-speed synchronous reluctance machine for flywheel applications," Ph.D. dissertation, Univ. California, Berkeley, CA, 1998

[26] J. R. Melcher, Continuum Electromechanics. Cambridge, MA: MIT Press, 1981

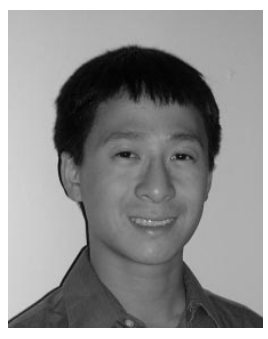

Perry Tsao (S'97-M'03) was born in Allentown, PA. $\mathrm{He}$ received the S.B. degree in electrical engineering and computer science from Massachusetts Institute of Technology (M.I.T.), Cambridge, in 1997, and the M.S. and Ph.D. degrees in electrical engineering from the University of California, Berkeley, in 1999 and 2003, respectively.

He has had internships at the M.I.T. Lincoln Laboratory (1995), the M.I.T. Media Lab (1996-1997), and Kensington Laboratories, Richmond, CA (1999). $\mathrm{He}$ is currently working on power electronics in hybrid electric vehicles at United Defense, L.P., Santa Clara, CA

Dr. Tsao authored a paper on magnetic bearings that received a Prize Paper Award at the 1999 IEEE Industry Applications Society Annual Meeting.

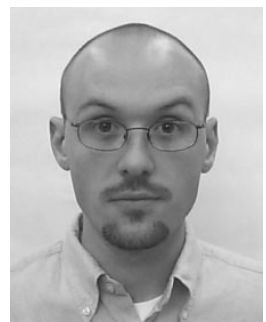

Matthew Senesky (S'03) grew up in Denville, NJ. $\mathrm{He}$ received the A.B. and B.E. degrees in 1998 and 1999, respectively, from Dartmouth College, Hanover, NH, and the the M.S. degree in 2003 from the University of California, Berkeley, where he is currently working toward the Ph.D. degree in electrical engineering.

His research interests include micro-scale power generation, electric machine design and control, and hybrid systems.

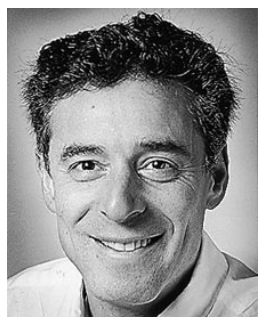

Seth R. Sanders (M'88) received S.B. degrees in electrical engineering and physics in 1981 and the S.M. and Ph.D. degrees in electrical engineering in 1985 and 1989, respectively, from Massachusetts Institute of Technology (M.I.T.), Cambridge.

He was a design engineer at the Honeywell Test Instruments Division, Denver, CO. Since 1989, he has been a member of the faculty of the Department of Electrical Engineering and Computer Sciences, University of California, Berkeley, where he is presently a Professor. His research interests are in high-frequency power conversion circuits and components, in design and control of electric machine systems, and in nonlinear circuit and system theory as related to the power electronics field. He is presently actively supervising research projects in the areas of flywheel energy storage, novel electric machine design, renewable energy, and digital pulsewidth-modulation strategies and associated IC designs for power conversion applications. During the 1992-1993 academic year, he was on industrial leave with National Semiconductor, Santa Clara, CA.

Prof. Sanders was a recipient of the NSF Young Investigator Award in 1993 He has served as Chair of the IEEE Technical Committee on Computers in Power Electronics, and as a Member-At-Large of the IEEE Power Electronics Society AdCom. He is a coauthor of papers awarded prizes by the IEEE Power Electronics and IEEE Industry Applications Societies. 